Check for updates

Cite this: RSC Adv., 2018, 8, 25983

\title{
Enhanced removal of hexavalent chromium from aqueous media using a highly stable and magnetically separable rosin-biochar-coated $\mathrm{TiO}_{2} @ \mathrm{C}$ nanocomposite $\dagger$
}

\author{
Balal Yousaf, (D) ab Guijian Liu, ${ }^{\text {*ab }}$ Qumber Abbas, ${ }^{a}$ Ruwei Wang, ${ }^{b}$ Habib Ullah, ${ }^{a}$ \\ Md Manik Mian, ${ }^{a}$ Amina ${ }^{c}$ and Audil Rashid ${ }^{d}$
}

Recently, nanosized metal-oxides have been extensively investigated for their ability to remove metal ions from aqueous media. However, the activity and capacity of these nanosized metal-oxides for removing metal ions decrease owing to their agglomeration in aqueous media. Herein, we synthesized a highly stable and magnetically separable rosin-biochar-coated (RBC) $\mathrm{TiO}_{2} \mathrm{aC}$ nanocomposite through a facile and environment-friendly wet chemical coating process, followed by a one-step heating route (pyrolysis) for efficient removal of $\mathrm{Cr}(\mathrm{vI})$ from aqueous solution. An array of techniques, namely, TEM, HRTEM, TEMEDS, XRD, FTIR, VSM, BET and TGA, were used to characterize the prepared nanocomposite. The pyrolysis of rosin into biochar and the fabrication of Fe onto the $\mathrm{RBC}-\mathrm{TiO}_{2} \mathrm{CC}$ nanocomposite were confirmed by FTIR and XRD examination, respectively. Moreover, TEM and HRTEM images and elemental mapping using TEM-EDS showed good dispersion of iron and carbon on the surface of the $\mathrm{RBC}-\mathrm{TiO}_{2} \mathrm{CC}$ nanocomposite. Sorption of $\mathrm{Cr}(\mathrm{VI})$ ions on the surface of the $\mathrm{RBC}-\mathrm{TiO}_{2} \mathrm{aC}$ nanocomposite was very fast and efficient, having a removal efficiency of $\sim 95 \%$ within the $1^{\text {st }}$ minute of reaction. Furthermore, thermodynamic analysis showed negative values of Gibb's free energy at all five temperatures, indicating that the adsorption of $\mathrm{Cr}(\mathrm{VI})$ ions on the $\mathrm{RBC}-\mathrm{TiO}_{2} \mathrm{aC}$ nanocomposite was favorable and spontaneous. Conclusively, our results indicate that the $\mathrm{RBC}-\mathrm{TiO}_{2} \mathrm{aC}$ nanocomposite can be used for efficient removal of $\mathrm{Cr}(\mathrm{vi})$ from aqueous media due to its novel synthesis and extraordinary adsorption efficacy during a short time period.

Received 3rd April 2018

Accepted 3rd July 2018

DOI: $10.1039 / \mathrm{c} 8 \mathrm{ra02860e}$

rsc.li/rsc-advances

\section{Introduction}

Heavy metal ions (HMIs) in surface and ground water, soil and sediments are posing severe threats to environmental and human health. ${ }^{1-8}$ Among these heavy metal ions (HMIs), chromium (Cr) is a highly toxic metal according to the United States Environmental Protection Agency (USEPA). ${ }^{9}$ The extensive use of chromium $(\mathrm{Cr})$ in different industries such as electroplatingoperations, tanning (leather), metal finishing, textiles, ${ }^{\mathbf{1 0}}$ steel

${ }^{a}$ CAS-Key Laboratory of Crust-Mantle Materials and the Environments, School of Earth and Space Sciences, University of Science and Technology of China, Hefei 230026, PR China. E-mail: lgj@ustc.edu.cn; Fax: +86-551-63621485; Tel: +86-551-63603714

${ }^{b}$ State Key Laboratory of Loess and Quaternary Geology, Institute of Earth Environment, The Chinese Academy of Sciences, Xi'an, Shaanxi 710075, China 'Anhui Province Key Laboratory of Farmland Ecological Conservation and Pollution Prevention, School of Resource and Environment, Anhui Agriculture University, Hefei 230026, PR China

${ }^{d}$ EcoHealth Research Group, Department of Environmental Sciences, PMAS Arid Agriculture University Rawalpindi, Pakistan

$\dagger$ Electronic supplementary information (ESI) available. See DOI: $10.1039 / \mathrm{c} 8 \mathrm{ra02860e}$ and metal alloy production, brass industry, cement industry, photographic components, and corrosive paint industry has resulted in its release into the ecosystem at concentrations that exceed environmental safety levels. ${ }^{11}$ The dominant forms of chromium in the natural environment are $\mathrm{Cr}(\mathrm{VI})$ and $\mathrm{Cr}(\mathrm{III})$. $\mathrm{Cr}(\mathrm{vI})$ is predominantly present in surface water due to good aeration and oxidizing conditions, while $\mathrm{Cr}(\mathrm{III})$ is prevalent in ground water due to reducing conditions. ${ }^{12,13} \mathrm{Cr}(\mathrm{vI})$ ions are relatively more toxic and carcinogenic than $\mathrm{Cr}$ (III) ions due to their higher solubility and mobility in the environment. ${ }^{\mathbf{1 1 , 1 3 , 1 4}}$ Thus, the presence of these ions can be detrimental to ecosystems as well as humans. Hence, there is a need to remove $\mathrm{Cr}(\mathrm{vI})$ from wastewater using a sustainable approach. ${ }^{15}$ Therefore, the development of efficient technologies for the removal of $\mathrm{Cr}(\mathrm{vI})$ from water has attracted considerable attention of researchers.

In recent decades, numerous water treatment strategies, such as coagulation, chemical precipitation, reverse osmosis, bacterial treatment, ion exchange, electrochemical treatment, nanofiltration and adsorption, have been developed to remove heavy metals, particularly $\mathrm{Cr}(\mathrm{vI})$, from contaminated/industrial effluents..$^{\mathbf{3} 16,17}$ Among these technologies, adsorption is 
regarded as one of the most promising approaches ${ }^{\mathbf{1 8}}$ due to its ease of operation, high efficiency, flexibility, convenience, and ease of regeneration of the adsorbent. ${ }^{19,20}$ Previous studies have reported numerous adsorbents for the removal of $\mathrm{Cr}(\mathrm{vI})$ such as nanosized metal oxides, ${ }^{21-25}$ clays, ${ }^{26}$ zeolites, ${ }^{27}$ magnetic nanocarbon $^{28-30}$ and activated carbon. ${ }^{31}$ However, most of the adsorbents have low surface area, low adsorption capacities and weak mechanical interactions. Recently, graphene oxide and reduced graphene oxide decorated with various metallic elements, with much higher adsorption capacity, have been used extensively for the removal of organic and inorganic pollutants. ${ }^{32,33}$ However, these composites are expensive as well as toxic, which have restricted their usage in removal techniques for contaminants. Hence, there is an urgent need to develop highly efficient and environment-friendly new adsorbents with large surface area, maximum adsorption capacity and high stability. Recently, an economical and sustainable wastewater treatment strategy, viz., the use of modified biochar and carbon nanomaterials, to remove metal ions from industrial wastewater is receiving increasing attention due to their high adsorption capacity and removal efficiency in a broad range of $\mathrm{pH}$ and temperature. Moreover, recent investigations have suggested that the modified-biochar/biochar-coated nanocomposites have high surface area and great affinity for adsorbing metal ions from aqueous solution. ${ }^{34}$ Other applications of carbon-based materials include fuel cells, self-healing of fiber composites, wireless power transfer, thermal conduction, silica microspheres and solar cells. ${ }^{35-41}$

In this study, $\mathrm{TiO}_{2}$ was selected as a porous solid substrate to support the fabrication of Fe-C composite on its surface. Moreover, magnetic iron oxide nanoparticles can be protected by inorganic mesoporous $\mathrm{TiO}_{2}$. Titanium (Ti) materials are porous and amphoteric, due to which they have become very attractive for the adsorption of metal ions [i.e., $\mathrm{Cr}(\mathrm{vI})]$ from water. ${ }^{\mathbf{1 1 , 4 2}}$ Additionally, $\mathrm{TiO}_{2}$ can be used in nanocomposite coatings for efficient fabrication of materials, oil/water separation, fabrication of solar cells and other applications. ${ }^{\mathbf{4 1 , 4 3 , 4 4}}$ Furthermore, rosin has become popular due to its unique molecular structure and its efficiency in removing contaminants. It is a resinous solid material obtained from pine and coniferous trees and contains a mixture of different isomerized acids ( $>90 \%) .{ }^{34,45}$ In this study, we report the novel formation of the RBC-TiO ${ }_{2} @ \mathrm{C}$ nanocomposite for efficient removal of $\mathrm{Cr}(\mathrm{vI})$. The magnetic nanoparticles of iron were immobilized onto the surface of the $\mathrm{RBC}^{-\mathrm{TiO}_{2}}$ @C nanocomposite by mesoporous $\mathrm{TiO}_{2}$ during the coating of rosin biochar. The as-synthesized

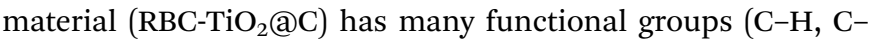
$\mathrm{OH}, \mathrm{COOH}, \mathrm{C}-\mathrm{O}-\mathrm{C}$, etc.) on the surface of the nanocomposite. At low $\mathrm{pH}$, the functional groups would become positively charged. Therefore, $\mathrm{Cr}(\mathrm{vI})$ can be adsorbed by these functional groups due to electrostatic attraction. ${ }^{34}$ Moreover, they can act as reducing agents and can cause reduction of $\mathrm{Cr}(\mathrm{VI})$ to $\mathrm{Cr}(\mathrm{III}) .{ }^{46}$ The RBC-TiO ${ }_{2} @ C$ nanocomposite was characterized using an array of techniques to confirm the fabrication of $\mathrm{Fe}$ and $\mathrm{C}$ on the surface of the as-synthesized nanocomposite and was used in this study to eliminate $\mathrm{Cr}(\mathrm{vI})$ from aqueous medium. The removal efficiency, adsorption capacity, adsorption kinetics and adsorption isotherms of the $\mathrm{RBC}^{-\mathrm{TiO}_{2}} @ \mathrm{C}$ nanocomposite were investigated in a broad range of $\mathrm{pH}$ and temperature.

\section{Experimental section}

\subsection{Chemicals and materials}

Rosin was purchased from Jitian Chemical Co. Ltd. China. Titanium dioxide $\left(\mathrm{TiO}_{2}\right)$, ferric chloride hexahydrate $\left(\mathrm{FeCl}_{3}\right.$ $\left.\cdot 6 \mathrm{H}_{2} \mathrm{O}\right)$, sodium hydroxide $(\mathrm{NaOH})$, potassium dichromate $\left(\mathrm{K}_{2} \mathrm{Cr}_{2} \mathrm{O}_{7}\right)$, ammonium hydroxide $\left(\mathrm{NH}_{4} \mathrm{OH}\right)$ and hydrochloric acid ( $\mathrm{HCl}$ ) were purchased from Sigma-Aldrich China Inc. Shanghai, China. All chemicals were of analytical grade (AR) and used without further purification. Ultrapure Milli-Q water (18.2 $\mathrm{M} \Omega \mathrm{cm})$ was used for all experimental solution preparations.

\subsection{Preparation of the $\mathrm{RBC}^{-\mathrm{TiO}_{2}}$ @C nanocomposite}

The RBC-TiO ${ }_{2} @ \mathrm{C}$ nanocomposite was synthesized (Scheme 1) by dissolving $9 \mathrm{~g}$ of ferric chloride hexahydrate $\left(\mathrm{FeCl}_{3} \cdot 6 \mathrm{H}_{2} \mathrm{O}\right)$

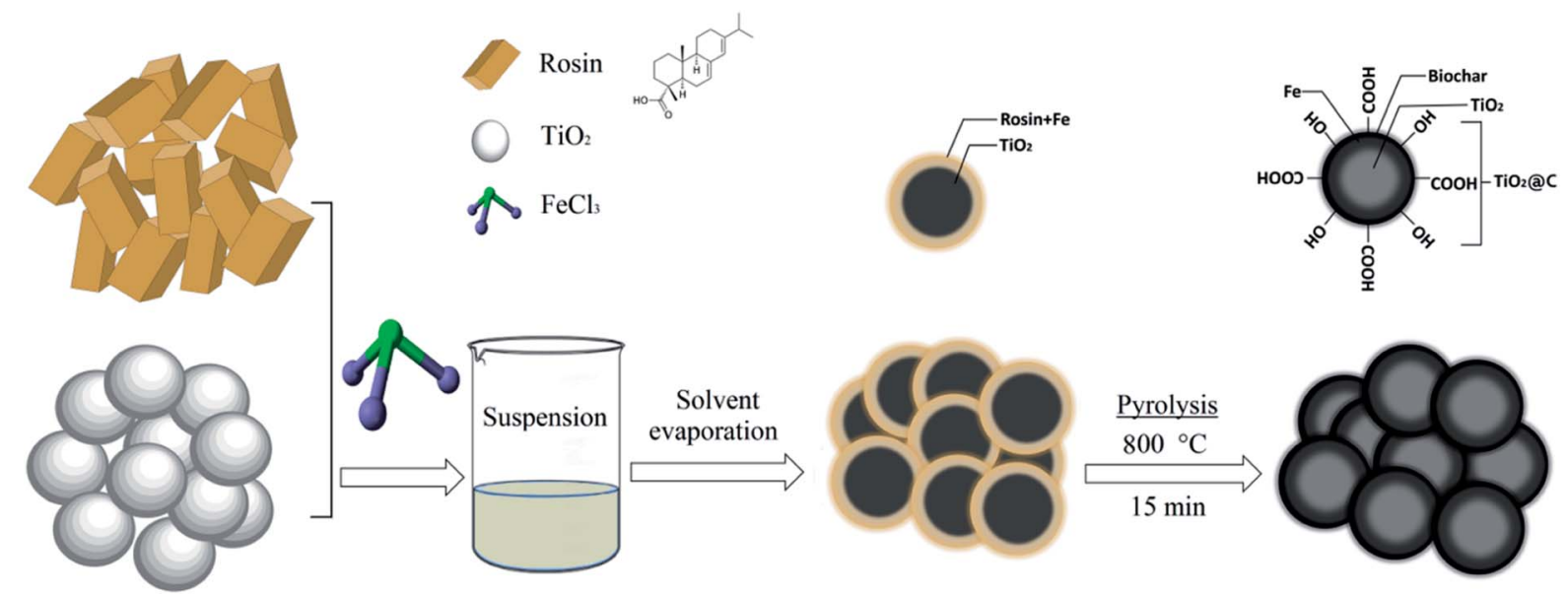

Scheme 1 Schematic diagram illustrating the synthesis of $\mathrm{BC}-\mathrm{TiO}_{2} \mathrm{aC}$ for efficient $\mathrm{Cr}(\mathrm{vI})$ removal. 
in $25 \mathrm{~mL}$ of deoxygenated water (deoxygenation using a LiquiCel® Membrane) in a $50 \mathrm{~mL}$ Pyrex beaker (borosilicate glass beaker), followed by addition of chitosan ( $2 \mathrm{~g})$. The $\mathrm{pH}$ of the $\mathrm{Fe}_{3} \mathrm{Cl} \cdot 6 \mathrm{H}_{2} \mathrm{O}$ working solution was fixed to 8 using $5 \% \mathrm{NH}_{4} \mathrm{OH}$. Next, $4 \mathrm{~g}$ of titanium dioxide $\left(\mathrm{TiO}_{2}\right)$ was slowly dissolved in $30 \mathrm{~mL}$ of ethyl alcohol and stirred mechanically for homogenous dispersion. Subsequently, $6 \mathrm{~g}$ of rosin was added into the above suspension and mixed well. Subsequently, ferric chloride solution was slowly spread into the above suspension and stirred for 1 hour. Then, the spongy emulsion was obtained by evaporating the solvent through heating at $70{ }^{\circ} \mathrm{C} .{ }^{11,34}$ Finally, the spongy emulsion was pyrolyzed in a tube furnace (BTF1200C, Anhui BEQ equipment, technology Co., Ltd, China) at $800{ }^{\circ} \mathrm{C}$ for $15 \mathrm{~min}$ (heating rate of $10^{\circ} \mathrm{C} \mathrm{min}{ }^{-1}$ ) in the presence of argon gas $\left(100 \mathrm{~mL} \mathrm{m^{-1 }}\right)$. After pyrolysis, a blackish powdered sample ( $\mathrm{RBC}-\mathrm{TiO}_{2} @ \mathrm{C}$ nanocomposite) was obtained. At the time of heating, Ti provides a giant substrate to support $\mathrm{Fe}^{3+}$ and rosin to generate a Fe-biochar complex on its surface. RBC was prepared by using a similar pyrolysis method without the addition of ferric chloride hexahydrate $\left(\mathrm{Fe}_{3}\right.$ $\left.\mathrm{Cl} \cdot 6 \mathrm{H}_{2} \mathrm{O}\right)$ and titanium dioxide $\left(\mathrm{TiO}_{2}\right)$.

\subsection{Physico-chemical characterization methods}

The morphological characteristics of the as-prepared material (RBC-TiO ${ }_{2} @ \mathrm{C}$ nanocomposite) were studied using transmission electron microscopy/high-resolution transmission electron microscopy (TEM/HRTEM) to confirm the carbon-rich core shell, lattice structure and flat faces of the samples. The distribution pattern of various elements (C, Ti and Fe) on the surface of the $\mathrm{RBC}^{-\mathrm{TiO}_{2}}$ @C nanocomposite was observed by elemental mapping using TEM-EDS (JEOL-2100F TEM/Scanning-TEM, JEOL Corporation), operating with an accelerating voltage of $200 \mathrm{kV}$. Thermogravimetric measurements were performed using a simultaneous thermal analyzer SDT Q600 (TA Instruments, USA) to confirm the presence of carbon and to check the thermal stability of the coated nanocomposite as a function of increasing temperature. Furthermore, the phase composition of the prepared samples was identified by X-ray powdered diffraction (Philips X'Pert-MPD diffractometer) patterns using $\mathrm{Cu} \mathrm{K} \alpha$ radiation $(\lambda=1.54056 \AA)$ at $40 \mathrm{kV}$ and $40 \mathrm{~mA}$ with a scan size of $0.02^{\circ}(2 \theta)$ and scan time of $4 \mathrm{~s}$ in the range of $20-70^{\circ}(2 \theta)$. Fourier transform infrared (FTIR) analysis was performed by using the $\mathrm{KBr}$ pellet technique in the mid infrared region. The surface chemistry of the as-prepared sample was studied by the $\mathrm{KBr}$ pellet technique using a Nicolet $^{\mathrm{TM}} 6700$ FT-IR spectrometer (Thermo Fisher Scientific, USA) in the mid infrared (IR) range (4000-900 $\mathrm{cm}^{-1}$ ) with $4 \mathrm{~cm}^{-1}$ resolution. IR spectra were recorded using OMNIC ${ }^{\text {TM }}$ Specta software (version 8.0). The surface area was assessed with the BrunauerEmmett and Teller (BET) technique by using a Micromeritics

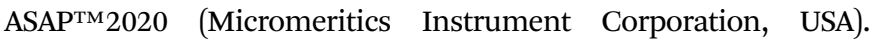
Adsorption/desorption isotherms of nitrogen $\left(\mathrm{N}_{2}\right)$ were determined at $77 \mathrm{~K}$ with a mechanical pore size and surface area analyzer (Autosorb-6iSA®, Quantachrome Instruments, FL 33426, USA). The pore size distribution was determined by the method of Barrett, Joyner, and Halenda (BJH). ${ }^{47}$

\subsection{Adsorption experiments}

The adsorption experiments were performed in a homothermal shaking incubator (JK-HIS-160AC, Shanghai Jingke Scientific Instrument Co., Ltd.) at $150 \mathrm{rpm}$ shaking speed to study the adsorption behaviors of $\mathrm{Cr}(\mathrm{vI})$ on the $\mathrm{RBC}^{-\mathrm{TiO}} \mathrm{O}_{2} @ \mathrm{C}$ nanocomposite. The stock solution of $\mathrm{Cr}(\mathrm{vI})\left(1000 \mathrm{mg} \mathrm{L}^{-1}\right)$ was prepared with $\mathrm{K}_{2} \mathrm{Cr}_{2} \mathrm{O}_{7}$ using Milli-Q water $(18.2 \mathrm{M} \Omega \mathrm{cm}) . \mathrm{Cr}(\mathrm{vI})$ solutions with initial concentrations of 25, 50, 75, 100, 125 and $150 \mathrm{mg} \mathrm{L}{ }^{-1}$ were prepared by diluting the concentrated stock. High density polyethylene (HDPE) bottles $(200 \mathrm{~mL})$ were used during the experiment. RBC-TiO ${ }_{2} @ \mathrm{C}$ nanocomposite $(0.08 \mathrm{~g})$ was added to $100 \mathrm{~mL}$ of working solutions [Cr(vI)] of various concentrations under agitation. For all adsorption experiments, the initial $\mathrm{pH}$ of the working solutions was fixed to 3 (with $0.1 \mathrm{~N}$ $\mathrm{HCl}$ or $0.1 \mathrm{~N} \mathrm{NaOH}$ solutions). The adsorption kinetics and adsorption isotherm were calculated by using a batch method from 288-308 $\mathrm{K}$ temperature and $25-150 \mathrm{mg} \mathrm{L}^{-1}$ initial concentration at $\mathrm{pH}$ 3. After the adsorption process, the samples were centrifuged at $4000 \mathrm{rpm}$ for $15 \mathrm{~min}$ (Thermo Scientific $^{\mathrm{TM}}$ Sorvall ${ }^{\mathrm{TM}}$ ST 40). The adsorbent was magnetically separated and the supernatant was collected by using a high density polyethylene syringe and filtered by $0.22 \mu \mathrm{m}$ disposable syringe filters and then analyzed by ICP-MS. A test experiment was conducted by analyzing the supernatant before and after filtration to confirm that there was no sorption loss during filtration. The adsorption capacity and adsorption efficiency were determined by the difference method $^{11,34,48}$ using the following formulae:

$$
\begin{gathered}
Q=\left(C_{0}-C_{\mathrm{e}}\right) \times \frac{V}{M} \\
E(\%)=\frac{\left(C_{0}-C_{0}\right)}{C_{0}} \times 100
\end{gathered}
$$

where, $Q$ represents the adsorption capacity $\left(\mathrm{mg} \mathrm{g}^{-1}\right), E$ denotes the removal efficiency (\%), $C_{0}$ and $C_{\mathrm{e}}$ represent the initial \& equilibrium concentrations of $\mathrm{Cr}(\mathrm{vI})$ in the solution $\left(\mathrm{mg} \mathrm{L}^{-1}\right)$, respectively, $V$ is the volume taken from the $\mathrm{Cr}(\mathrm{vI})$ solution (L), and $m$ is the mass of the RBC-TiO ${ }_{2} @ C$ nanocomposite that was used $(\mathrm{g})$.

\subsection{Kinetics and adsorption studies}

The two most popular kinetics models and four adsorption isotherm models, used in this study to investigate the kinetic mechanism and adsorption behavior, are presented in Table S1. $\dagger$ Both these pseudo-first-order and pseudo-second-order kinetics models were employed to determine the kinetics mechanism and adsorption capacity $\left(q_{\mathrm{e}}\right)$ of $\mathrm{Cr}(\mathrm{vI})$ on the

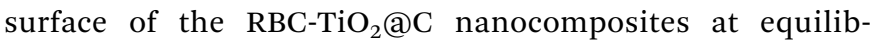
rium. ${ }^{\mathbf{4 8 , 4 9}}$ In addition, the modeling of experimental adsorption isotherm data was performed using four adsorption isotherm models [Langmuir, Freundlich, Temkin and Dubinin-Radushkevich (D-R)] to provide in depth information about the adsorption behavior of the $\mathrm{RBC}^{-\mathrm{TiO}_{2}}$ @C nanocomposites. Detailed information of the kinetics and equilibrium models (ESI $\dagger$ ) and their equations (general or non- 
linear form and linear form), $x$ and $y$ values, and their slopes and intercepts are presented in Table S1.†

\subsection{Effect of $\mathbf{p H}$}

The influence of $\mathrm{pH}$ on the $\mathrm{Cr}(\mathrm{vI})$ removal efficiency of RBC$\mathrm{TiO}_{2} @ \mathrm{C}$ was determined by using the standard method. ${ }^{11}$ $\mathrm{Cr}(\mathrm{vI})$ solution $(100 \mathrm{~mL})$ was transferred into a series of high density polyethylene (HDPE) bottles. The initial $\mathrm{pH}\left(\mathrm{pH}_{i}\right)$ of the $\mathrm{Cr}(\mathrm{vI})$ solution was set to $2,4,6,8,10$ and 12 by adding $0.1 \mathrm{~N} \mathrm{HCl}$ or $0.1 \mathrm{~N} \mathrm{NaOH}$ solutions. The initial concentration of the experimental solution was set to $100 \mathrm{mg} \mathrm{Cr}(\mathrm{VI}) \mathrm{L}^{-1}$. All the solutions were treated with $0.8 \mathrm{~g} \mathrm{~L}^{-1}$ of $\mathrm{RBC}^{-\mathrm{TiO}_{2}}$ @C nanocomposites for $24 \mathrm{~h}$ in a homothermal shaking incubator (JK-HIS-160AC, Shanghai Jingke Scientific Instrument Co., Ltd.) at $288 \mathrm{~K}$. The solution was then centrifuged, filtered and collected for analysis. The final $\mathrm{pH}\left(\mathrm{pH}_{f}\right)$ of the filtrate was observed accurately using a portable multi-parameter meter (Orion Star A329, Thermo Fisher Scientific, USA). The difference between the initial and final $\mathrm{pH}$ was determined by the equation $\Delta \mathrm{pH}=\mathrm{pH}_{i}-\mathrm{pH}_{f}$. The final $\mathrm{Cr}(\mathrm{vI})$ concentration in the supernatant and removal efficiency by $\mathrm{RBC}^{-\mathrm{TiO}_{2} @ \mathrm{C}}$ nanocomposites was determined as described above.

\subsection{Thermodynamics study}

Thermodynamics study provides a deep understanding of the change in energies $\left(\Delta G^{0}\right)$ during the adsorption process. ${ }^{48}$ The thermodynamic parameters were evaluated using the following equations:

$$
\begin{gathered}
\Delta G^{0}=-R T \ln K_{\mathrm{c}} \\
\ln K_{\mathrm{c}}=\left(\Delta S^{0} / R\right)-(\Delta H / R T)
\end{gathered}
$$

where $\Delta G^{0}$ is the standard Gibbs free energy $\left(\mathrm{kJ} \mathrm{mol}^{-1}\right), R$ is the universal gas constant $\left(8.314 \mathrm{~J} \mathrm{~mol}^{-1} \mathrm{~K}^{-1}\right), T$ is the absolute temperature $(\mathrm{K}), K_{\mathrm{c}}$ is the thermodynamic equilibrium constant, $\Delta S^{0}$ is the standard entropy change and $\Delta H$ is the standard enthalpy change in the adsorption process for $\mathrm{Cr}(\mathrm{vI})$ on the RBC-TiO ${ }_{2} @ \mathrm{C}$ nanocomposite.

\section{Results and discussion}

\subsection{Synthesis and characterization of the $\mathrm{RBC}^{-\mathrm{TiO}_{2}}$ @C nanocomposite}

Unlike the more expensive and energy consuming traditional solid-state technologies, through which only low adsorption
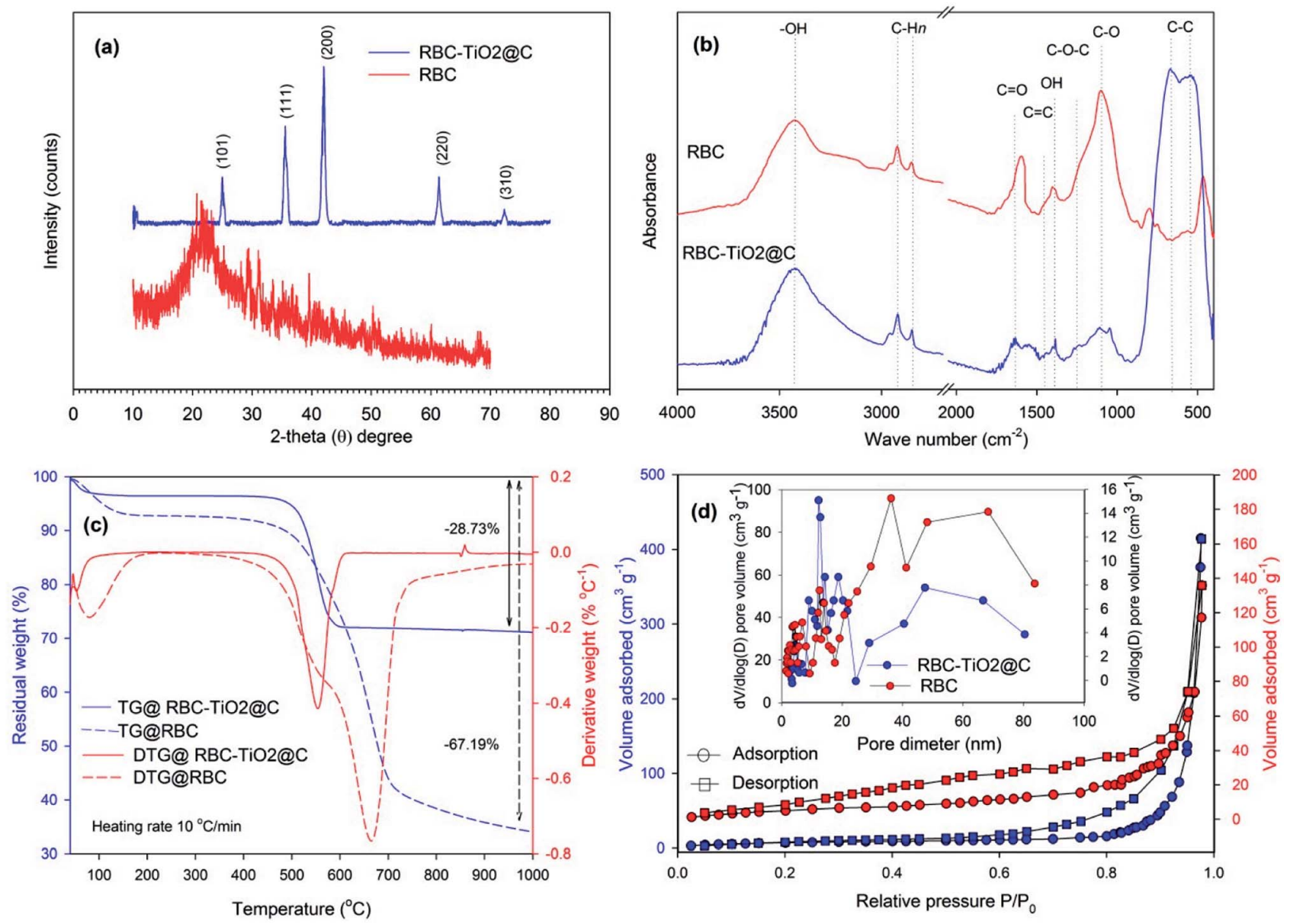

Fig. 1 Characterization of $\mathrm{RBC}$ and the $\mathrm{RBC}-\mathrm{TiO}_{2} \mathrm{aC}$ nanocomposite: (a) X-ray powder diffraction (XRD) pattern; (b) FTIR spectra; (c) TGA/DTG of $\mathrm{RBC}$ and the $\mathrm{RBC}-\mathrm{TiO}_{2} \mathrm{CC}$ nanocomposite calcined in air atmosphere up to $1000^{\circ} \mathrm{C}$; (d) $\mathrm{N}_{2}$ adsorption-desorption isotherms at $77 \mathrm{~K}$ and the pore-size distribution curve from the desorption branch using the $\mathrm{BJH}$ model. 
capacity materials could be obtained due to poor complexes between carbon and metallic ions, our novel methodology that illustrates the synthesis of the $\mathrm{RBC}^{-\mathrm{TiO}_{2}}$ @C nanocomposite is efficient in removing $\mathrm{Cr}(\mathrm{vI})$ from aqueous medium (Scheme 1). The RBC-TiO ${ }_{2} @ C$ nanocomposite can be prepared via chemical coating of $\mathrm{TiO}_{2}$ nanoparticles with dissolved rosin, followed by one-step heating route (pyrolysis) under oxygen free environment; detailed explanations are presented in the experimental section. Furthermore, the as-synthesized sample $\left(\mathrm{RBC}^{-\mathrm{TiO}_{2}} @ \mathrm{C}\right.$ nanocomposite) was characterized using an array of techniques, namely, TEM, HRTEM, TEM-EDS, FTIR, XRD, VSM, Brunauer-Emmett and Teller (BET) and TGA.

The structures of the as-prepared $\mathrm{RBC}$ and $\mathrm{RBC}^{-\mathrm{TiO}_{2}}$ @C nanocomposite were investigated by XRD analysis (Fig. 1). The XRD pattern for RBC revealed a wide range strong diffraction peak at $2 \theta=20^{\circ}$, which indicates the presence of carbon in the form of graphite crystallite. This typical broad diffraction peak of carbon is attributed to the abundance of various functional groups on the surfaces of the RBC. ${ }^{50}$ Moreover, major sharp characteristic peaks of $\mathrm{Fe}_{2} \mathrm{O}_{3}$ at $35.49^{\circ}, 43.38^{\circ}$ and $62.47^{\circ}(2 \theta)$ are observed in the $\mathrm{RBC}-\mathrm{TiO}_{2} @ \mathrm{C}$ nanocomposite, which indicate that the as-synthesized nanocomposite has desirable magnetic characteristics. ${ }^{34}$ The $\mathrm{RBC}^{-\mathrm{TiO}_{2}}$ @C nanocomposite also exhibited reflection peaks at $2 \theta=25.21^{\circ}, 27.29^{\circ}$ and $74.3^{\circ}$, which can be well fitted to the typical crystallographic planes of anatase (I41/amd), a trace of rutile-phase $(P 42 / \mathrm{mnm})$ and TiC $(F d \overline{3} m)$, respectively. ${ }^{51}$ The reflections of $\mathrm{Fe}_{2} \mathrm{O}_{3}$ and the crystal planes of $\mathrm{TiO}_{2}$, indexed to (101), (105), (111), (200), (220) and (310), confirmed the successful preparation of the biocharcoated magnetic $\mathrm{RBC}-\mathrm{TiO}_{2}$ @C nanocomposite. ${ }^{52}$

The magnetic property of the $\mathrm{RBC}^{-\mathrm{TiO}_{2}} @ \mathrm{C}$ nanocomposite was measured by VSM at room temperature in an applied magnetic field sweeping from -5000 to $5000 \mathrm{G}$ (Fig. 2) and the hysteresis loop indicates that the $\mathrm{RBC}-\mathrm{TiO}_{2} @ \mathrm{C}$ nanocomposite sample possesses superparamagnetic behavior with no remanence or coercivity. ${ }^{52}$ Furthermore, the minor reflection peak at $2 \theta=10.1^{\circ}$ indicates a trace of carbon, which corresponds to the typical diffraction peak of graphene oxide. Apart from these findings, no carbons were identified in the XRD pattern probably due to the existence of amorphous carbon. In addition, thermogravimetric analysis (TGA, Fig. 1c) confirms the existence of carbon-compounds $(28.73 \%$ carbon) in the RBC$\mathrm{TiO}_{2} @ \mathrm{C}$ nanocomposite and also shows the thermal stability of the coated samples as a function of temperature. ${ }^{53}$

In order to identify the carbon-based compounds that have functional groups on the surface of $\mathrm{RBC}$ and the $\mathrm{RBC}-\mathrm{TiO}_{2} @ \mathrm{C}$ nanocomposite, FTIR spectroscopy analysis was performed

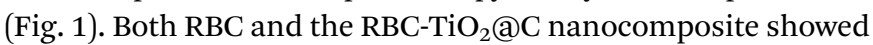
a broad (3150-3700 $\mathrm{cm}^{-1}$ ) band centered at $3400 \mathrm{~cm}^{-1}$, which mainly represents the $-\mathrm{OH}$ stretching vibrations of adsorbed water and hydrous compounds. The peaks at $850-900 \mathrm{~cm}^{-1}$, $1030-1080 \mathrm{~cm}^{-1}, 1350-1430 \mathrm{~cm}^{-1}, 1480-1530 \mathrm{~cm}^{-1}$ and $1550-$ $1700 \mathrm{~cm}^{-1}$ correspond to the $\mathrm{C}-\mathrm{H}, \mathrm{C}-\mathrm{O}, \mathrm{O}-\mathrm{H}, \mathrm{C}=\mathrm{C}$ and $\mathrm{C}=\mathrm{O}$ stretching vibrations of the $\mathrm{sp}^{2}$ carbon skeletal network, respectively. Moreover, peaks located at 2850 and $2910 \mathrm{~cm}^{-1}$ correspond to $\mathrm{C}-\mathrm{H}_{n}$ stretching vibrations of the alkyl/aliphatic

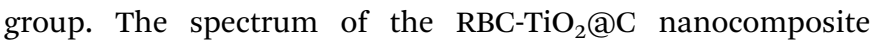
showed two distinct bands at 550 and $675 \mathrm{~cm}^{-1}$, which could be the characteristic peaks of $\mathrm{Fe}_{2} \mathrm{O}_{3}$ and $\mathrm{TiO}_{2}$, respectively. ${ }^{\mathbf{1 1 , 4 9 , 5 4}}$

To obtain further information about the surface morphology

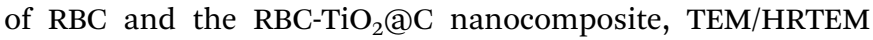
imaging was performed (Fig. 3). ${ }^{11,34}$ Fig. 3a and b represent the TEM and HRTEM images of RBC, respectively. The TEM images in Fig. 3c-e show the particle size (average size: 25-40

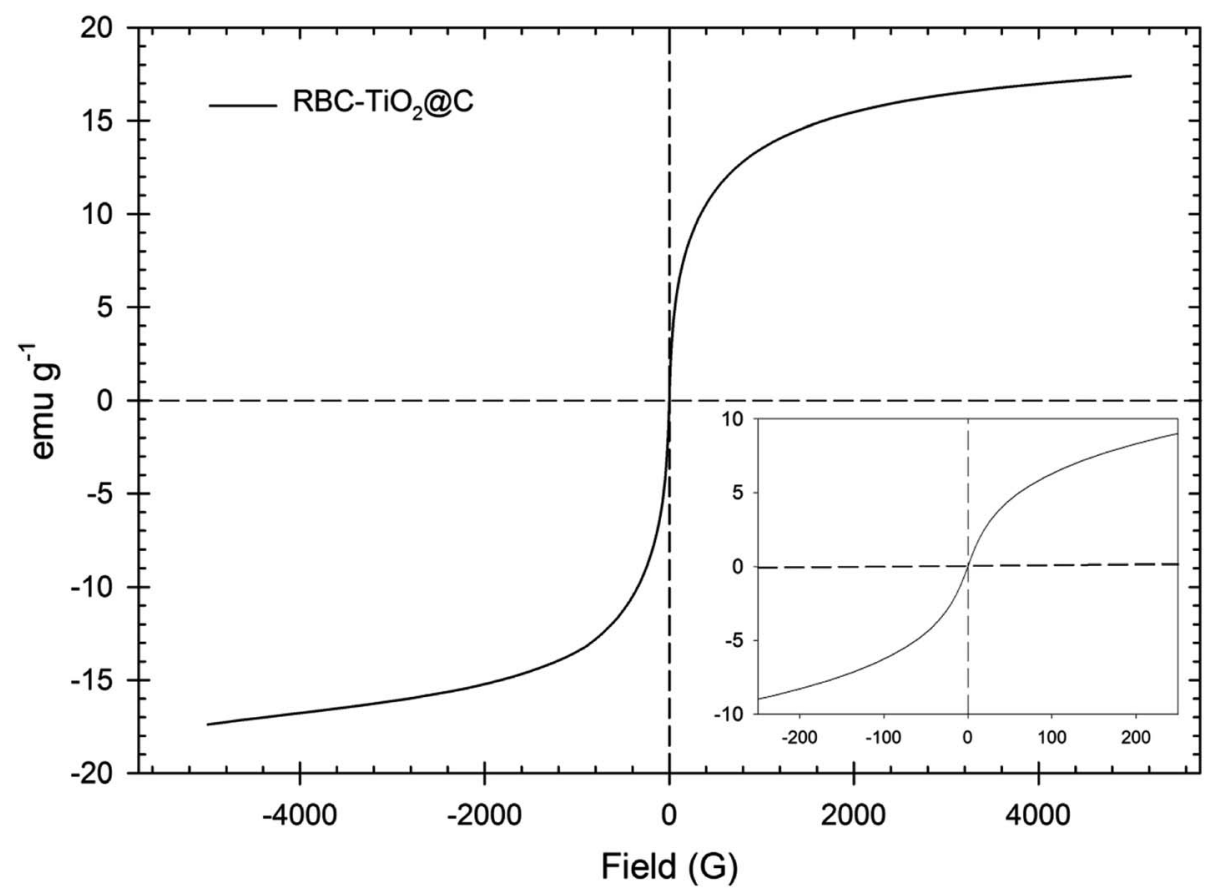

Fig. 2 VSM measurement of the synthesized biochar-coated $\mathrm{RBC}-\mathrm{TiO}_{2} \mathrm{aC}$ nanocomposite sample. 


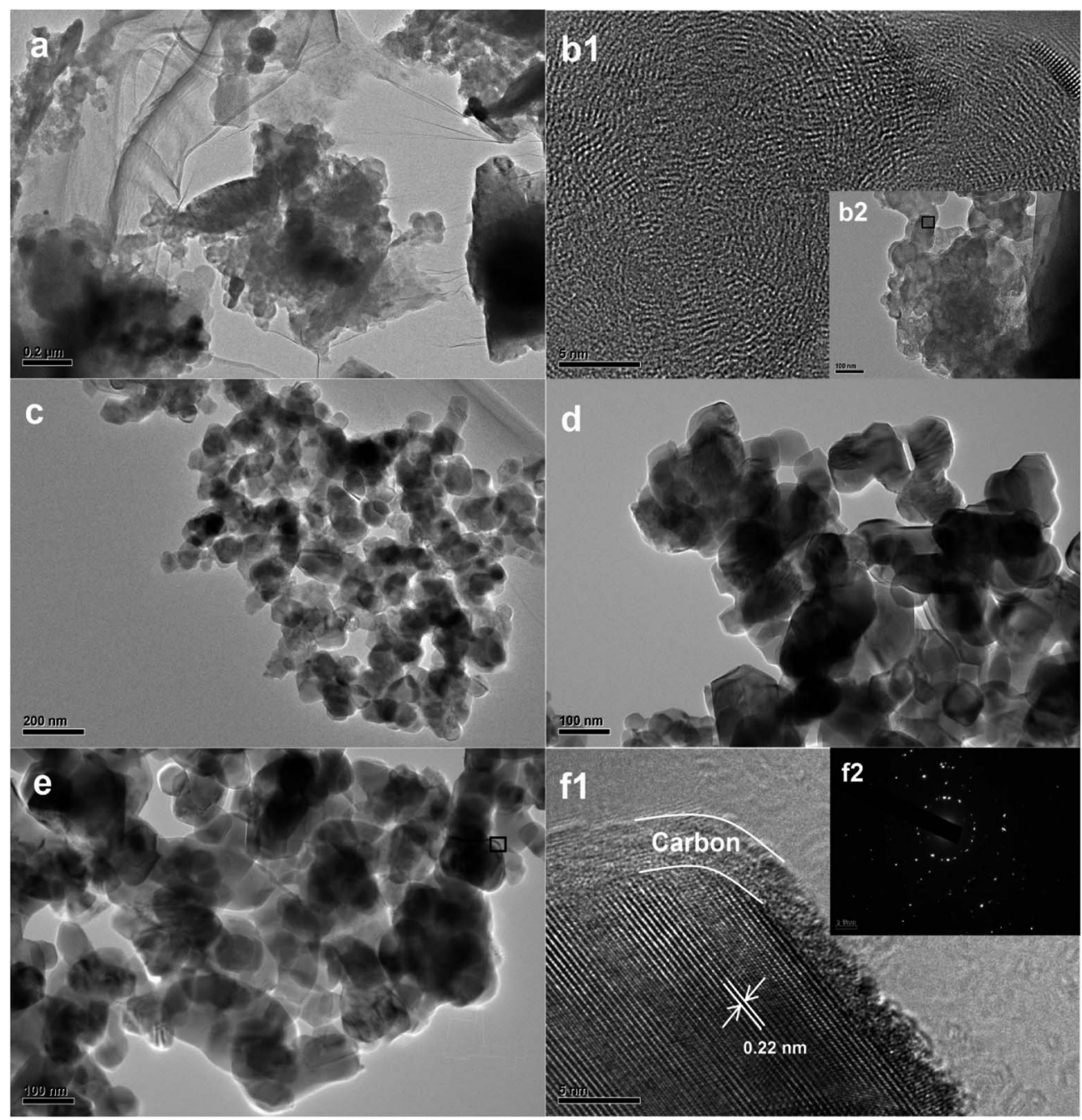

Fig. 3 TEM images of $(a$ and $b) \mathrm{RBC}$ and $(c-f)$ the $\mathrm{RBC}-\mathrm{TiO}_{2} \mathrm{aC}$ nanocomposite. ( $\mathrm{b} 1$ and $\mathrm{f} 1$ ) Magnified images, (f1) HRTEM image showing a $\mathrm{C}$-rich core-shell structure and (f2) SAED patterns of the $\mathrm{RBC}-\mathrm{TiO}_{2} \mathrm{CC}$ nanocomposite.

$\mathrm{nm}$ ) of the $\mathrm{RBC}-\mathrm{TiO}_{2} @ \mathrm{C}$ nanoparticles and the continuous wrapping layer of carbon on the surface of the $\mathrm{TiO}_{2}$ nanoparticles to form a RBC-TiO ${ }_{2} @ \mathrm{C}$ nanocomposite. The HRTEM/ SAED analysis (Fig. 3f1 and f2) confirms the presence of the uniform graphitized-carbon layer of nano thickness ( $c a .4-5$ $\mathrm{nm}$ ) on the surface of $\mathrm{RBC}^{-\mathrm{TiO}_{2}}$ @C. Furthermore, in order to investigate the distribution pattern of different elements ( $\mathrm{Ti}, \mathrm{Fe}$ and C; Fig. 4a and b) on the surface of the $\mathrm{RBC}^{-\mathrm{TiO}_{2}}$ @C nanocomposite, transmission electron microscopy combined with EDS mapping images (TEM-EDS) are presented in Fig. 4. The TEM-EDS elemental analysis shows a well-dispersed and uniform distribution of carbon (Fig. 4c) and iron (Fig. 4d) on the surface of the Ti nanoparticle (Fig. 4e) to form a well-fabricated RBC-TiO ${ }_{2} @ \mathrm{C}$ nanocomposite with large surface area (consistent with the BET analysis: Fig. 1). ${ }^{49}$

\subsection{Adsorption capacity and removal efficiency of the RBC- $\mathrm{TiO}_{2} @ \mathrm{C}$ nanocomposite}

The $\mathrm{Cr}(\mathrm{vI})$ removal efficiency of $\mathrm{RBC}$ and the $\mathrm{RBC}^{-\mathrm{TiO}_{2} @ \mathrm{C}}$ nanocomposites was investigated by using $0.8 \mathrm{~g} \mathrm{~L}^{-1}$ dose of adsorbent at $288 \mathrm{~K}$ (Fig. S1 and S2 $\uparrow$ ). Sorption of $\mathrm{Cr}(\mathrm{vI})$ ions was faster and more efficient with the $\mathrm{RBC}^{-\mathrm{TiO}_{2}}$ @C nanocomposites than with RBC under the same conditions. With an initial concentration of $\mathrm{Cr}(\mathrm{vI})$ of $100 \mathrm{mg} \mathrm{L}^{-1}$ at $288 \mathrm{~K}$ and $\mathrm{pH} 4$, in the first minute of the reaction, the $\mathrm{Cr}(\mathrm{vr})$ removal efficiency of the $\mathrm{RBC}-\mathrm{TiO}_{2} @ \mathrm{C}$ nanocomposites was $55.68 \%$, which is very high compared to RBC (5.24\%). After 1 minute, adsorption slowed down in the case of the $\mathrm{RBC}^{-\mathrm{TiO}_{2}} @ \mathrm{C}$ nanocomposites and the removal efficiency reached equilibrium after 10 minutes, while the equilibrium time for RBC was 30 minutes. After 100 minutes of reaction time, the $\mathrm{Cr}(\mathrm{vI})$ removal efficiencies of the $\mathrm{RBC}^{-} \mathrm{TiO}_{2} @ \mathrm{C}$ nanocomposites and RBC were $59.53 \%$ and $27.32 \%$, respectively. These results indicate that the interaction between $\mathrm{RBC}$ and $\mathrm{Cr}(\mathrm{VI})$ was weak. Moreover, the high removal efficiency of the $\mathrm{RBC}-\mathrm{TiO}_{2} @ \mathrm{C}$ nanocomposites is due to the $\alpha-\mathrm{Fe}_{2} \mathrm{O}_{3}$ because they have very strong affinity towards $\mathrm{Cr}(\mathrm{vI})$ ions. $^{34}$ The EDS and XPS analyses, which confirm the

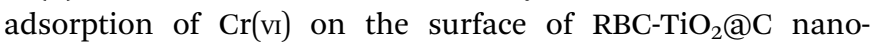
composites after treatment and reduction of $\mathrm{Cr}(\mathrm{VI})$ to $\mathrm{Cr}(\mathrm{III})$, are presented in Fig. S3 and S4, $\dagger$ respectively. In the first minute of the adsorption process, the active sites for the binding of $\mathrm{Cr}(\mathrm{vI})$ 

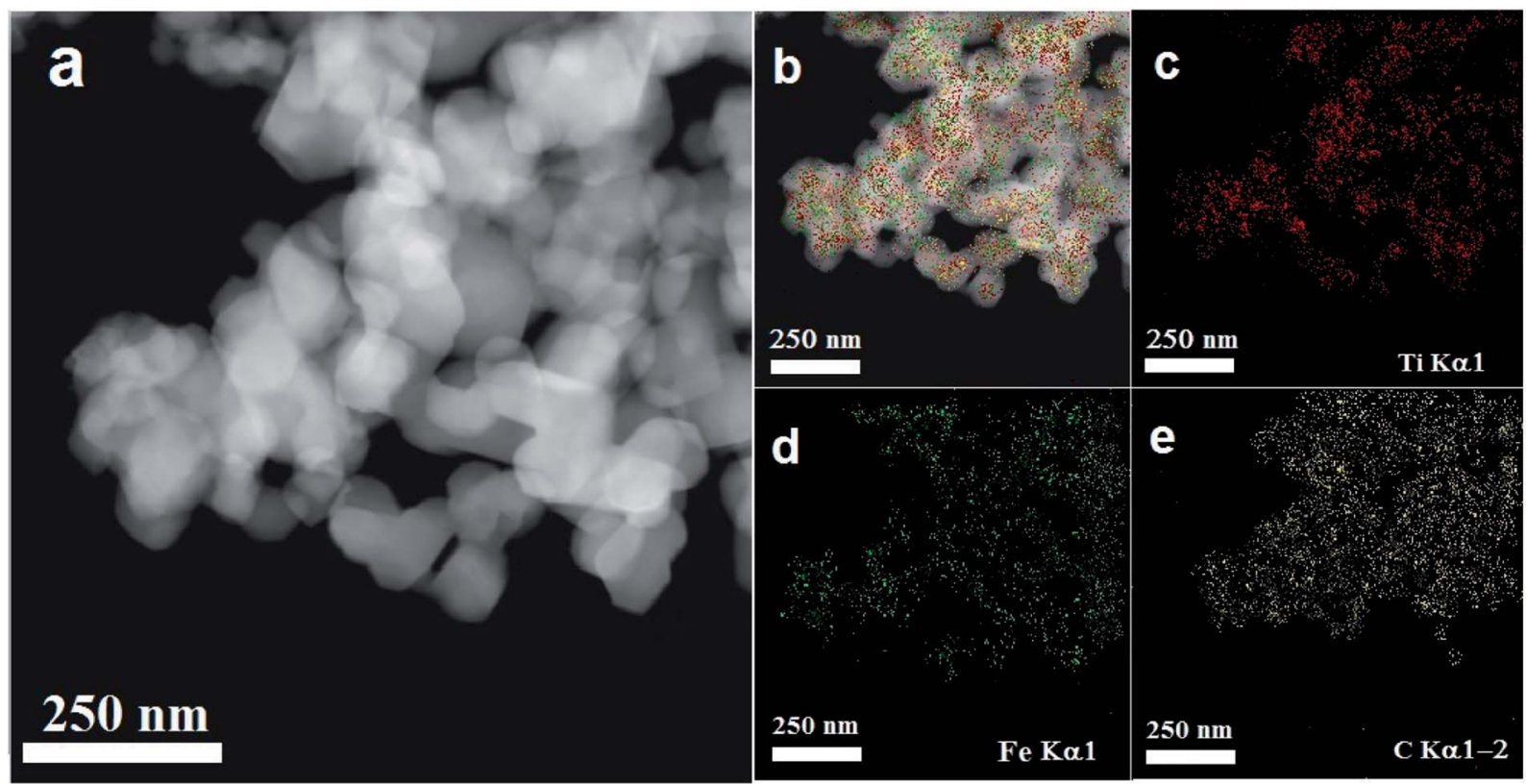

Fig. 4 Surface morphology and TEM-EDS elemental mapping of the $\mathrm{RBC}-\mathrm{TiO}_{2} \mathrm{aC}$ nanocomposite (a-e). The EDS mapping shows the good dispersion of (d) $\mathrm{Fe}$ and (e) $\mathrm{C}$ on the surface of the $\mathrm{RBC}-\mathrm{TiO}_{2} \mathrm{CC}$ nanocomposite.
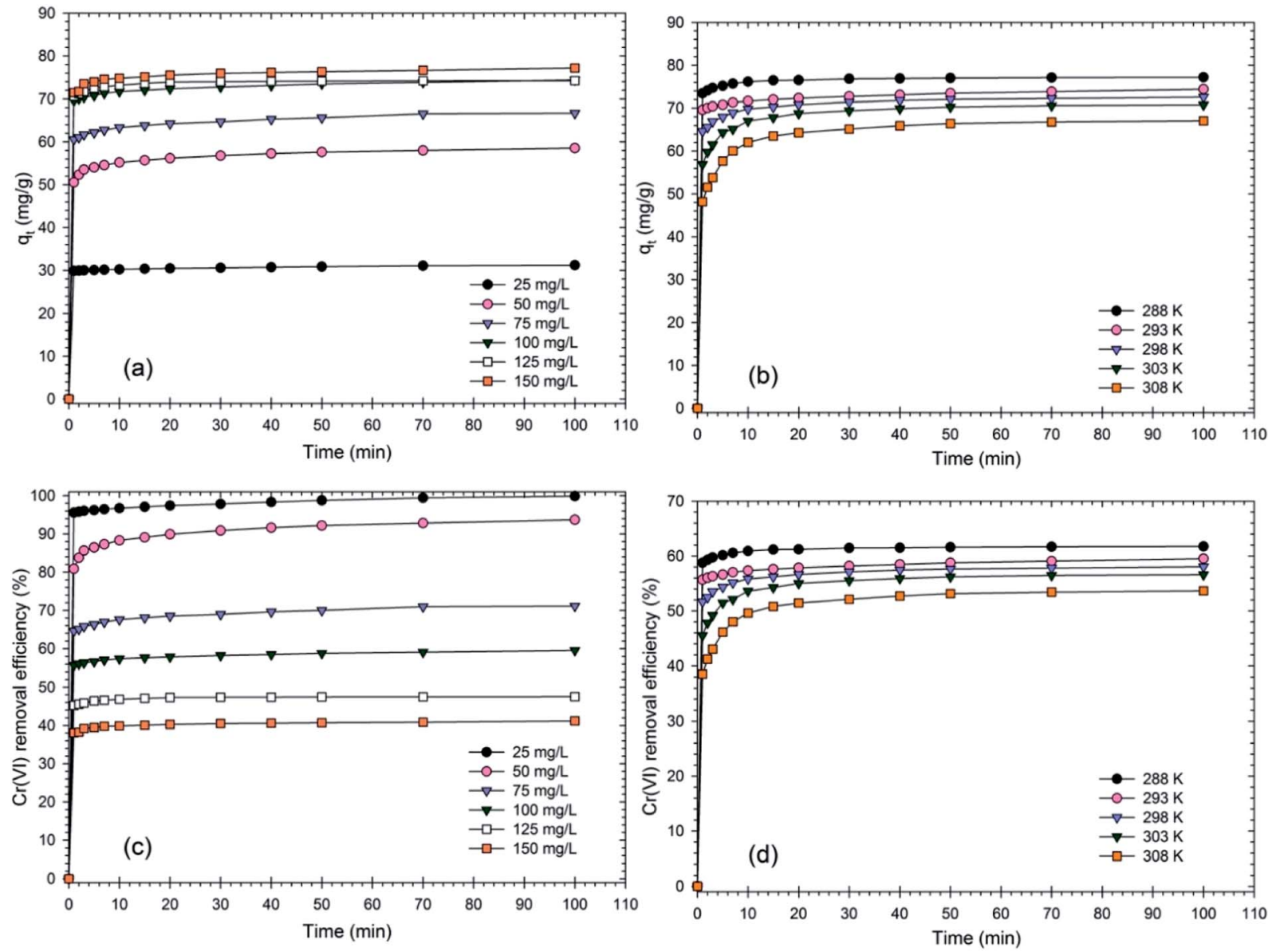

Fig. 5 Effect of contact time associated with the initial concentration ( $\mathrm{mg} \mathrm{kg}^{-1}$ ) of $\mathrm{Cr}(\mathrm{VI})$ and temperature (K) on (a and b) the $\mathrm{Cr}(\mathrm{VI})$ adsorption capacity $\left(\mathrm{mg} \mathrm{g}^{-1}\right.$ ) and (c and d) the removal efficiency (\%) of the RBC-TiO, aC nanocomposite (dosage $\mathrm{aO}_{2} .8 \mathrm{~g} \mathrm{~L}^{-1} ; \mathrm{pH}_{4} ; 288 \mathrm{~K}$ temperature; $100 \mathrm{mg} \mathrm{L}^{-1}$ initial concentration; $150 \mathrm{rpm}$ shaking speed). 


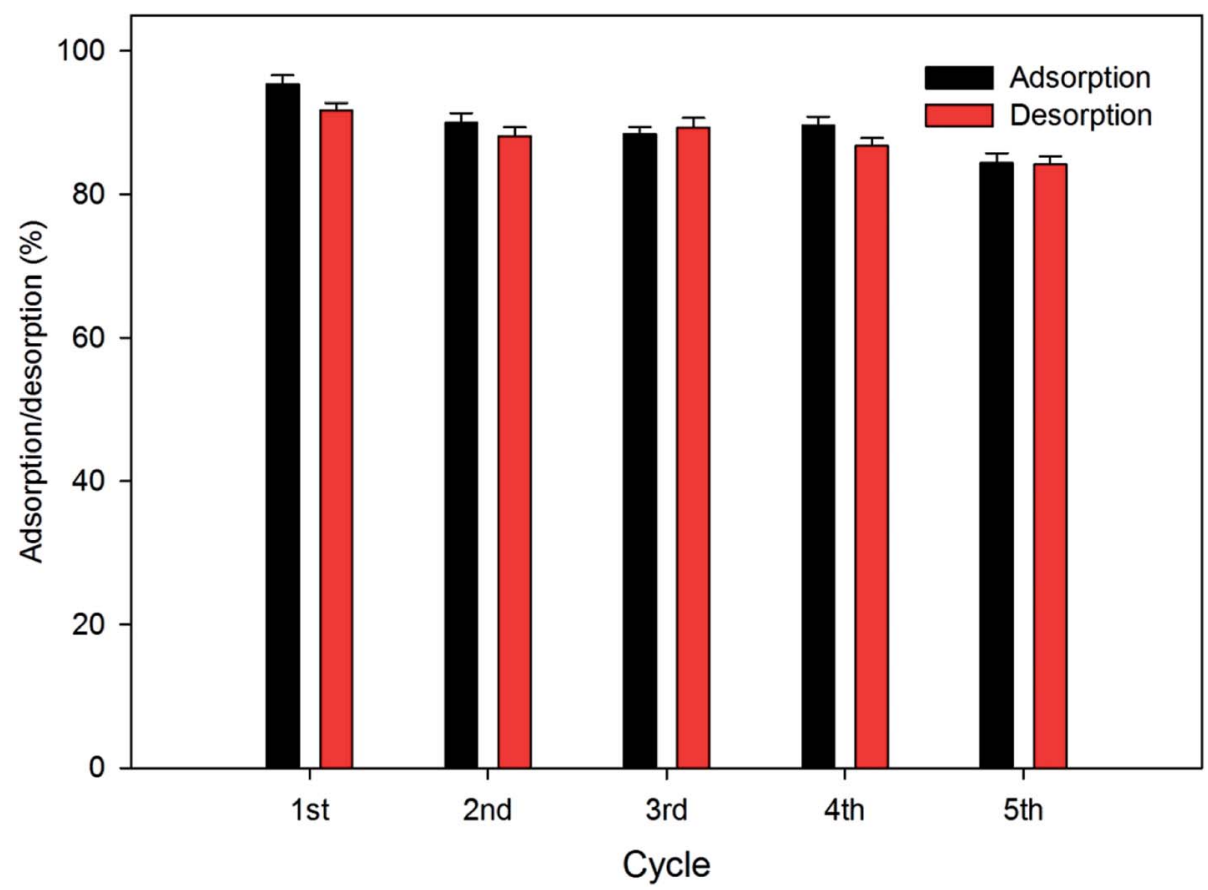

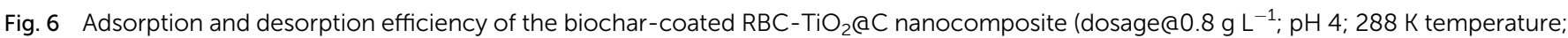
$25 \mathrm{mg} \mathrm{L}^{-1}$ initial concentration; 150 rpm shaking speed).

were sufficient. Subsequently, all the binding sites were occupied by $\mathrm{Cr}(\mathrm{VI})$ ions and there were no free sites for more adsorption. ${ }^{11,34}$ On the basis of its high removal efficiency, RBC$\mathrm{TiO}_{2} @ \mathrm{C}$ was chosen for further experiments. In addition, the effects of coexisting ions on the removal of $\mathrm{Cr}(\mathrm{vI})$ were investigated to determine the adsorption specificity (Fig. S5 $†$ ).

The effect of contact time on $q_{\mathrm{e}}\left(\mathrm{mg} \mathrm{g}^{-1}\right)$ and the removal efficiency (\%) of the $\mathrm{RBC}^{-\mathrm{TiO}_{2}}$ @C nanocomposites associated with the initial concentration of $\mathrm{Cr}(\mathrm{vI})$ and temperature is shown in Fig. 5. The adsorption properties of an adsorbent can be evaluated by the contact time between the adsorbate and adsorbent. ${ }^{55}$ The $\mathrm{RBC}^{-\mathrm{TiO}_{2}}$ @C nanocomposites exhibited high removal efficiency during the first minute and then, the adsorption capacity remained almost constant with time, suggesting that the $\mathrm{RBC}^{-\mathrm{TiO}_{2}}$ @C nanocomposites can quickly reach its equilibrium state. ${ }^{34}$ It was found that the adsorption

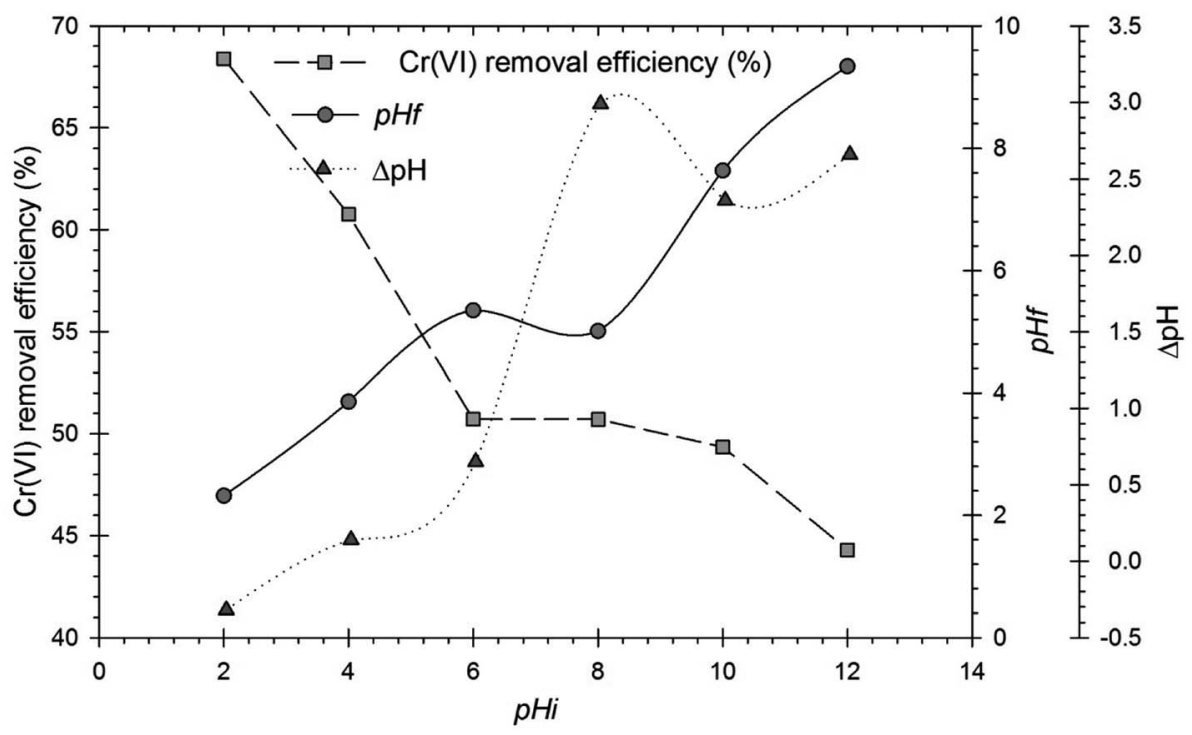

Fig. 7 Effect of initial $\mathrm{pH}\left(\mathrm{pH}_{i}\right)$ on the removal efficiency of $\mathrm{Cr}(\mathrm{vl})$ by the $\mathrm{RBC}-\mathrm{TiO}_{2} @ \mathrm{C}$ nanocomposite, $\mathrm{pH}$ and $\Delta \mathrm{pH}$. $\mathrm{Here}, \mathrm{pH}$ and $\Delta \mathrm{pH}$ represent the final $\mathrm{pH}$ and change in $\mathrm{pH}$ after the adsorption experiment, respectively (dosage $0.8 \mathrm{~g} \mathrm{~L}^{-1} ; 100 \mathrm{mg} \mathrm{kg}^{-1}$ initial concentration; $288 \mathrm{~K}$ temperature; $150 \mathrm{rpm}$ shaking speed). 
process was very quick and efficient. Fig. 5 indicates that the adsorption capacity after one minute of reaction time increased from $29.86 \mathrm{mg} \mathrm{g}^{-1}$ to $71.43 \mathrm{mg} \mathrm{g}^{-1}$ with an increase in the initial $\mathrm{Cr}(\mathrm{vI})$ concentration from 25 to $150 \mathrm{mg} \mathrm{L}^{-1}$. At the end of the adsorption process, the adsorption capacity increased from $31.21 \mathrm{mg} \mathrm{g}^{-1}$ to $77.2 \mathrm{mg} \mathrm{g}^{-1}$ with an increase in concentration from 25 to $150 \mathrm{mg} \mathrm{L}^{-1}$. The removal efficiency decreased with the increase in initial concentration of $\mathrm{Cr}(\mathrm{vI})$.

Removal efficiency decreased from $95.56 \%$ to $38.1 \%$ in the first minute of the reaction with the increase in initial concentration from $25 \mathrm{mg} \mathrm{L}^{-1}$ to $150 \mathrm{mg} \mathrm{L}^{-1}$. After 100 minutes of reaction time, removal efficiency decreased from $99.88 \%$ to $41.17 \%$ as the concentration increased from $25 \mathrm{mg} \mathrm{L}^{-1}$ to $150 \mathrm{mg} \mathrm{\textrm {L } ^ { - 1 }}$. It can be concluded from the results that the removal efficiency decreased with an increase in the $\mathrm{Cr}(\mathrm{vI})$ concentration in the working solution. In addition, the adsorption capacity and removal efficiency associated with different temperatures is shown in Fig. 5. The results indicate that the adsorption capacity and removal efficiency decreased with the increase in temperature. Adsorption capacity decreased from $77.2 \mathrm{mg} \mathrm{g}^{-1}$ to $67.06 \mathrm{mg} \mathrm{g}^{-1}$ and the removal efficiency decreased from $61.76 \%$ to $53.65 \%$ as the temperature increased from $288 \mathrm{~K}$ to $308 \mathrm{~K}$. Furthermore, the adsorption and desorption efficiency of the biochar-coated $\mathrm{RBC}^{-\mathrm{TiO}_{2}}$ @C nanocomposite during 5 cycles is presented in Fig. 6, which shows $84.39 \%$ adsorption after the fifth cycle.

\subsection{Effect of initial $\mathbf{p H}$ on removal efficiency}

One of the key components influencing the adsorption of $\mathrm{Cr}(\mathrm{vI})$ is the $\mathrm{pH}$ of the solution because it affects the charge on the adsorbent surface and the ionic state of the functional groups on the adsorbent surface. The impact of solution $\mathrm{pH}$ on the removal efficiency of $\mathrm{Cr}(\mathrm{vI})$ by using $\mathrm{RBC}^{-\mathrm{TiO}_{2}}$ @C nanocomposites was investigated in the $\mathrm{pH}$ range from 2 to 12 at 288 $\mathrm{K}$ with $100 \mathrm{mg} \mathrm{g}^{-1}$ of $\mathrm{Cr}(\mathrm{vI})$ in the working solution and a $0.8 \mathrm{~g}$ $\mathrm{L}^{-1}$ dose of adsorbent. Fig. 7 clearly shows that the removal efficiency of $\mathrm{Cr}(\mathrm{vI})$ ions on the $\mathrm{RBC}^{-\mathrm{TiO}_{2}}$ @C nanocomposites is maximal (68.39\%) at the strongly acidic $\mathrm{pH}$ of 2 . The removal efficiency of the $\mathrm{RBC}-\mathrm{TiO}_{2} @ \mathrm{C}$ nanocomposites significantly decreases to about $50.76 \%$ when the $\mathrm{pH}$ increases from 2 to 4 . When the $\mathrm{pH}$ of the solution increased from 4 to 10 , the removal percentage remains almost constant, but decreased to $44.29 \%$ as the $\mathrm{pH}$ further increased to 12 .

The dominant species of $\mathrm{Cr}(\mathrm{vI})$ at $\mathrm{pH} 2$ to 6 are $\mathrm{HCrO}_{4}{ }^{1-}$ and $\mathrm{Cr}_{2} \mathrm{O}_{7}{ }^{2-}$, while at $\mathrm{pH}$ higher than 6 , the dominant species is $\mathrm{CrO}_{4}{ }^{2-} \cdot{ }^{\mathbf{1 1 , 5 6}}$ The removal efficiency of $\mathrm{Cr}(\mathrm{vI})$ increased with the decrease in $\mathrm{pH}$ of the solution because the electrostatic
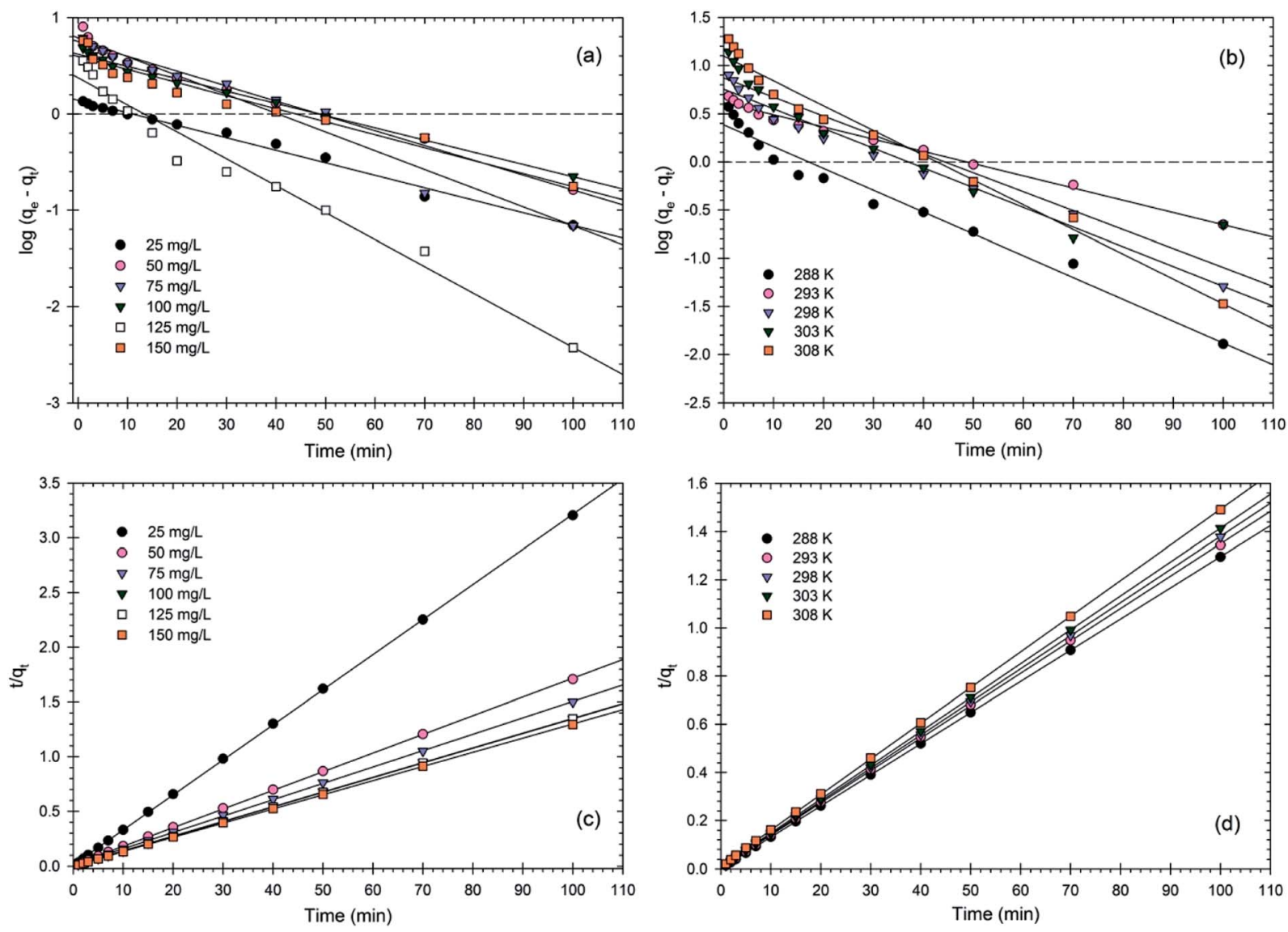

Fig. 8 ( $a$ and b) Pseudo first-order and (c and d) pseudo second-order kinetic model fits for $\mathrm{Cr}(\mathrm{vI})$ adsorption onto the RBC-TiO ${ }_{2} \mathrm{aC}$ nanocomposite at various initial concentrations $\left(\mathrm{mg} \mathrm{kg}^{-1}\right.$ ) of $\mathrm{Cr}(\mathrm{vl})$ and different temperatures (K) (dosages $0.8 \mathrm{~g} \mathrm{~L}^{-1} ; \mathrm{pH}^{2} ; 288 \mathrm{~K} ; 150 \mathrm{rpm}$ shaking speed). 
Table 1 Comparison of the pseudo first-order and pseudo second-order rate constants for $\mathrm{Cr}(\mathrm{vI})$ adsorption onto the RBC-TiO 2 (aC nanocomposite at different initial concentrations and temperatures

\begin{tabular}{|c|c|c|c|c|c|c|c|c|}
\hline Parameter & & $q_{\mathrm{e}}(\exp )\left(\mathrm{mg} \mathrm{g}^{-1}\right)$ & $q_{\mathrm{e}}(\mathrm{cal})\left(\mathrm{mg} \mathrm{g}^{-1}\right)$ & $k_{1}\left(\min ^{-1}\right)$ & $r_{1}^{2}$ & $q_{\mathrm{e}}(\mathrm{cal})\left(\mathrm{mg} \mathrm{g}^{-1}\right)$ & $k_{2}\left(\mathrm{~g} \mathrm{mg}^{-1} \min ^{-1}\right)$ & $r_{2}^{2}$ \\
\hline & 50 & 58.56 & 54.38 & 0.0355 & 0.9581 & 58.48 & 0.0311 & 0.9999 \\
\hline & 75 & 66.69 & 61.72 & 0.0449 & 0.9327 & 66.67 & 0.0300 & 0.9998 \\
\hline & 100 & 74.41 & 72.84 & 0.0292 & 0.9787 & 74.07 & 0.0380 & 0.9998 \\
\hline \multirow[t]{5}{*}{ Temperature (K) } & 288 & 77.20 & 75.56 & 0.0525 & 0.9226 & 77.51 & 0.0925 & 0.9999 \\
\hline & 293 & 74.41 & 72.84 & 0.0292 & 0.9787 & 74.07 & 0.0380 & 0.9999 \\
\hline & 298 & 72.56 & 68.29 & 0.0472 & 0.9538 & 72.46 & 0.0373 & 0.9999 \\
\hline & 303 & 70.76 & 70.05 & 0.0603 & 0.9677 & 70.92 & 0.0258 & 0.9999 \\
\hline & 308 & 67.06 & 66.71 & 0.0592 & 0.9568 & 67.57 & 0.0181 & 0.9999 \\
\hline
\end{tabular}

attraction is strong between the adsorbent and adsorbate at low $\mathrm{pH}$, while electrostatic repulsion is dominant at high $\mathrm{pH} .{ }^{34}$ At low $\mathrm{pH}$, the surface charge of the adsorbent becomes positive due to the high concentration of $\mathrm{H}^{+}$in the aqueous solution, which increases the adsorption. At high $\mathrm{pH}$, the adsorbent becomes negatively charged and more $\mathrm{OH}^{-}$compete with $\mathrm{Cr}(\mathrm{vI})$ ions, which subsequently decreases the removal efficiency of $\mathrm{Cr}(\mathrm{vI})$ ions. ${ }^{11,57,58}$

The final $\mathrm{pH}$ of the treated solution was also estimated and it was observed that the $\mathrm{RBC}-\mathrm{TiO}_{2} @ \mathrm{C}$ nanocomposites could slightly increase the final $\mathrm{pH}$ of the solution that was initially set to $\mathrm{pH}$ 2. However, the final $\mathrm{pH}$ decreased for solutions that were initially set to $\mathrm{pH}>2$ (Fig. 7). The decrease in final $\mathrm{pH}$ may be due to the low molecular weight compounds from the pyrolysis of the rosin. It is assumed that the LMWCs maintained the solution $\mathrm{pH}$ at a value lower than the initial $\mathrm{pH} \cdot{ }^{34}$ Zeta potential measurements were used to estimate the point of zero charge

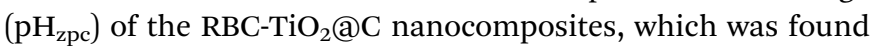
to be around 3.5 (Fig. 7). pHzpc is the point where the surface of an adsorbent has neutral charge. ${ }^{11}$ When the $\mathrm{pH}$ of the solution is greater than pHzpc, the surface charge of the $\mathrm{RBC}^{-\mathrm{TiO}_{2}}$ @C nanocomposites is negative and when the $\mathrm{pH}$ is less than pHzpc, the surface of the $\mathrm{RBC}^{-\mathrm{TiO}_{2}}$ @C nanocomposites is positively charged. On the basis of pHzpc and removal efficiency, in this study, $\mathrm{pH}=3$ was considered as the optimum $\mathrm{pH}$ for maximum adsorption of $\mathrm{Cr}(\mathrm{vI})$ ions.

\subsection{Adsorption kinetics}

The adsorption kinetics of $\mathrm{Cr}(\mathrm{vI})$ ions at different concentrations of $\mathrm{Cr}(\mathrm{vI})$ and different temperatures (Fig. 8) were explained
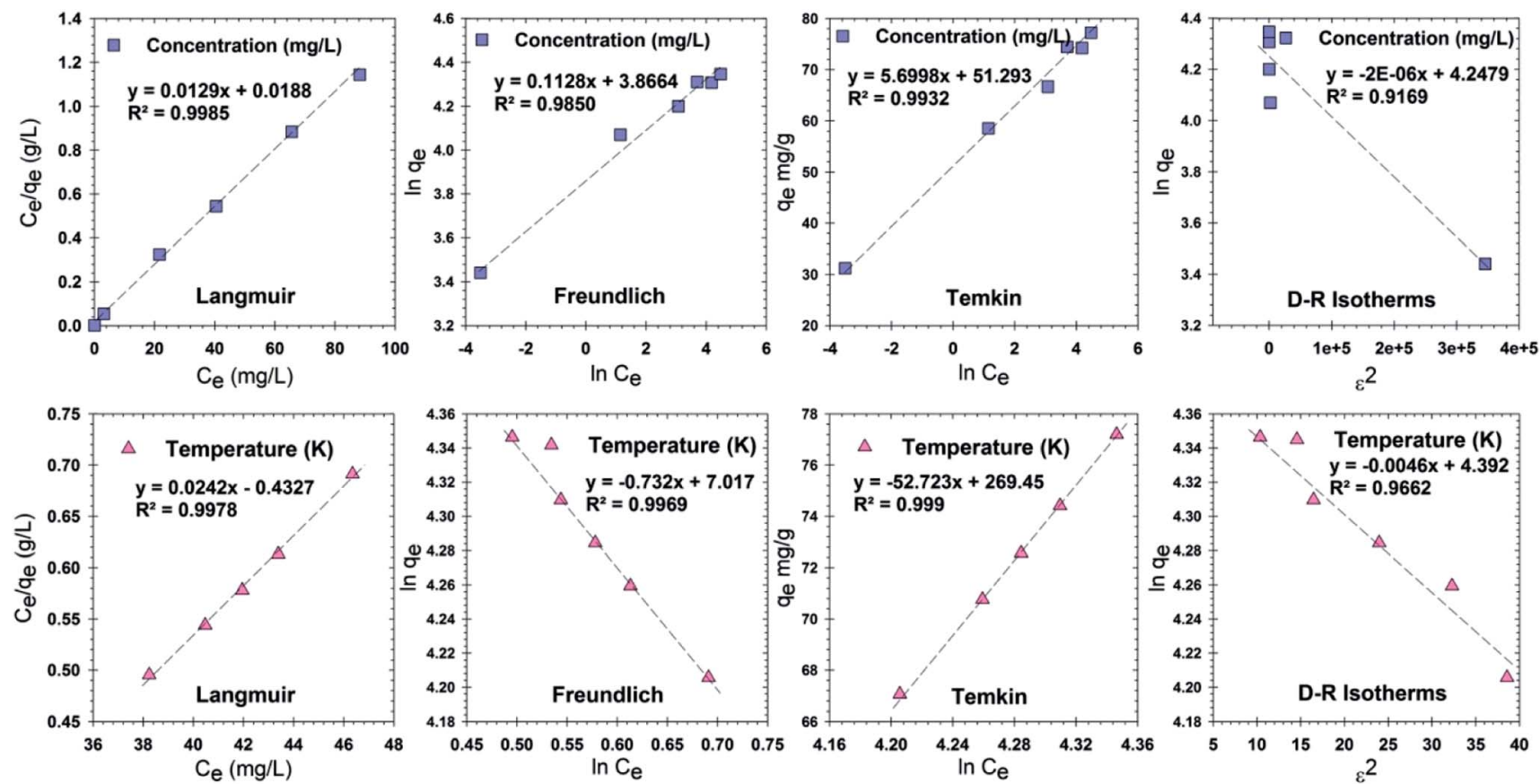

Fig. 9 Linear fit for adsorption isotherm models (Langmuir, Freundlich, Temkin and Dubinin-Radushkevich (D-R)) for Cr(vi) adsorption onto the $\mathrm{RBC}-\mathrm{TiO}_{2} \mathrm{CC}$ nanocomposite at various initial concentrations $\left(\mathrm{mg} \mathrm{kg}^{-1}\right)$ and temperatures $(\mathrm{K})$. 
Table 2 Constant parameters and correlation coefficients of $\mathrm{Cr}(\mathrm{vI})$ adsorption onto the $\mathrm{RBC}-\mathrm{TiO} \mathrm{O}_{2} \mathrm{C}$ nanocomposite calculated for various adsorption models (Langmuir, Freundlich, Temkin and Dubinin-Radushkevich (D-R)) at different initial concentrations (mg kg ${ }^{-1}$ ) and temperatures (K)

\begin{tabular}{|c|c|c|c|c|c|c|}
\hline & 0.9985 & 77.52 & 0.6862 & 0.9978 & 41.32 & 0.1614 \\
\hline \multirow[t]{2}{*}{ Freundlich } & $r^{2}$ & $n$ & $K_{\mathrm{F}}$ & $r^{2}$ & $n$ & $K_{\mathrm{F}}$ \\
\hline & 0.9850 & 8.87 & 47.77 & 0.9969 & -1.37 & 111.54 \\
\hline \multirow[t]{2}{*}{ Temkin } & $r^{2}$ & $b$ & $K_{\mathrm{T}}$ & $r^{2}$ & $b$ & $K_{\mathrm{T}}$ \\
\hline & 0.9932 & 427.38 & 8.99 & 0.9990 & 46.20 & 5.83 \\
\hline $\begin{array}{l}\text { Dubinin-Radush } \\
\text { kevich (D-R) }\end{array}$ & $r^{2}$ & $\beta$ & $q_{\mathrm{d}}$ & $r^{2}$ & $\beta$ & $q_{\mathrm{d}}$ \\
\hline
\end{tabular}

by two popular kinetic models: pseudo-first order model and pseudo-second order model. ${ }^{3,59}$ The particulars of these model equations are summarized in Table S1. $\dagger$ It can be evaluated from the results in Table 1 and Fig. 8, that although the values of $r_{1}^{2}$ are considerably high, the experimental adsorption capacity $q_{\mathrm{e}}(\exp )$ differed from the calculated adsorption capacity $q_{\mathrm{e}}$ (cal). This suggests that adsorption mechanism is not well fit by a pseudo-first order kinetic model.

As shown in Table 1 and Fig. 8, the values of $r_{2}{ }^{2}$ at all $\mathrm{Cr}(\mathrm{vr})$ concentrations and temperatures exceed 0.99 (almost near unity), suggesting that the adsorption mechanism is chemisorption..$^{3,20,60,61}$ The values of calculated adsorption capacity $q_{\mathrm{e}}$ (cal) were also very close to the experimental adsorption capacity $q_{\mathrm{e}}$ (exp), suggesting that the adsorption kinetic data for the $\mathrm{Cr}(\mathrm{vI})$ ions are well fit by the pseudo-second order model. From the kinetics results, it was concluded that the adsorption process is chemical in nature. Similar results for $\mathrm{Cr}(\mathrm{vI})$ have been shown for $\mathrm{Bt} / \mathrm{Bc} / \alpha-\mathrm{Fe}_{2} \mathrm{O}_{3},{ }^{34}$ the PPy-TiP nanocomposite ${ }^{11}$ and $\mathrm{Fe}_{3} \mathrm{O}_{4} @ \mathrm{mTiO}_{2} @ \mathrm{GO}^{3}$

\subsection{Adsorption isotherm}

Analysis of adsorption isotherms provides information about the performance of the adsorbent. Four isotherm models, Freundlich, Langmuir, Temkin and Dubinin-Radushkevich (D-

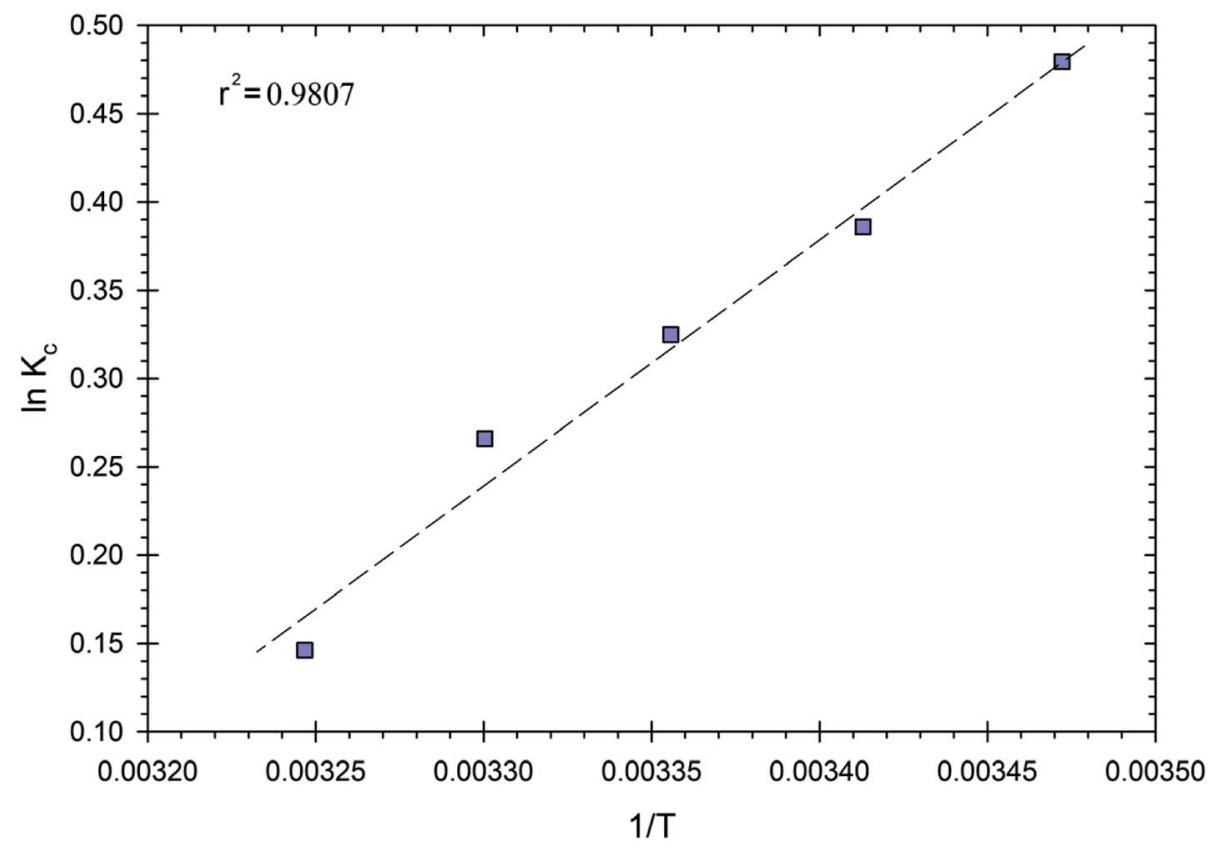

Fig. 10 Plot of $\ln K_{\mathrm{c}}$ versus $1 / T$ for the $\mathrm{RBC}-\mathrm{TiO}_{2} \mathrm{QC}$ nanocomposite. 
$\mathrm{R})$ were used to analyze the data. Adsorption isotherms of $\mathrm{Cr}(\mathrm{vI})$ on the $\mathrm{RBC}-\mathrm{TiO}_{2} @ \mathrm{C}$ nanocomposites at various concentrations and temperatures are displayed in Fig. 9. The Langmuir adsorption isotherm model assumes that all the adsorption sites are homogeneous and it describes monolayer coverage of $\mathrm{Cr}(\mathrm{vI})$ ions onto the surface of the adsorbent. ${ }^{62}$ In the Langmuir model, $K_{\mathrm{L}}\left(\mathrm{L} \mathrm{mg}^{-1}\right)$ is the constant related to the affinity of the active sites for adsorption and $q_{\mathrm{m}}\left(\mathrm{mg} \mathrm{g}^{-1}\right)$ is the theoretical maximum adsorption capacity. The maximum adsorption capacities for $\mathrm{Cr}(\mathrm{vI})$ at different concentrations and temperatures are 77.52 and $41.32 \mathrm{mg} \mathrm{g}^{-1}$, respectively. These values are exceptionally higher than those for the previously reported adsorbent, PPy-TiP, ${ }^{11}$ which indicates the efficacy of the RBC$\mathrm{TiO}_{2} @ \mathrm{C}$ nanocomposites towards $\mathrm{Cr}(\mathrm{vI})$ removal. The Freundlich isotherm model describes multi-layer sorption with the heterogeneous surfaces of an adsorbent. ${ }^{62}$ In this model, $K_{\mathrm{F}}$ and $n$ are the constants related to adsorption intensity and surface heterogeneity, respectively. A value of $n$ greater than 1 represents good adsorption and a more heterogeneous adsorbent surface and a value near to or equal to 1 represents more homogeneous surfaces. The Temkin adsorption isotherm model indicates the chemisorption process and suggests that the energy decreases as the interaction between adsorbent and adsorbate increases. ${ }^{63}$ In this model, $K_{\mathrm{T}}$ and $b$ are the Temkin isotherm constants related to the maximum binding energy and heat of adsorption. The Dubinin-Radushkevich (D-R) isotherm model indicates the physical or chemical adsorption mechanism. In this model, $q_{\mathrm{d}}\left(\mathrm{mg} \mathrm{g}^{-1}\right)$ is the $\mathrm{D}-\mathrm{R}$ constant, $\beta$ is related to mean free energy and $\varepsilon$ is the energy related to the Polanyi potential. The correlation coefficient $\left(r^{2}\right)$ is lowest for this model at different $\mathrm{Cr}(\mathrm{vI})$ concentrations and temperatures (Table 2), indicating that adsorption of $\mathrm{Cr}(\mathrm{vI})$ on the $\mathrm{RBC}^{-\mathrm{TiO}} \mathrm{O}_{2}$ @C nanocomposites is not physical. ${ }^{\mathbf{1 1 , 4 8}}$

\subsection{Thermodynamic behavior}

Thermodynamic parameters were used to gain an in-depth understanding of the phenomenon of adsorption and its mechanism. ${ }^{21}$ The effects of temperature on $\mathrm{Cr}(\mathrm{vI})$ ion adsorption on the surface of the $\mathrm{RBC}^{-\mathrm{TiO}_{2}}$ @C nanocomposites were studied at 288, 293, 298, 303 and $308 \mathrm{~K}$. The thermodynamic parameters such as standard enthalpy change $\left(\Delta H^{0}\right)$ and standard entropy change $\left(\Delta S^{0}\right)$ were obtained from the slope and intercept of the $\ln K_{\mathrm{c}}$ vs. $1 / T$ plot (Fig. 10). Gibb's free energy $\left(\Delta G^{0}\right)$ can be calculated by using eqn (3) and the relevant results are displayed in Table 3. The value of Gibb's free energy was negative at all five temperatures, which indicated that the adsorption of $\mathrm{Cr}(\mathrm{vI})$ ions

Table 3 Thermodynamic parameters for $\mathrm{Cr}(\mathrm{VI})$ adsorption onto the $\mathrm{RBC}-\mathrm{TiO}_{2} \mathrm{QC}$ nanocomposite

\begin{tabular}{lcllll}
\hline $\begin{array}{l}\text { Temperature } \\
(\mathrm{K})\end{array}$ & $\Delta G^{0}$ & $\ln K_{\mathrm{c}}$ & $\begin{array}{l}\Delta H \\
\left(\mathrm{~kJ} \mathrm{~mol}^{-1}\right)\end{array}$ & $\begin{array}{l}\Delta S^{0} \\
\left(\mathrm{~J} \mathrm{~mol}^{-1} \mathrm{~K}^{-1}\right)\end{array}$ & $r^{2}$ \\
\hline 288 & -1147.83 & 0.4794 & 167.55 & 0.524 & 0.9807 \\
293 & -940.1 & 0.3859 & & & \\
298 & -804.78 & 0.3248 & & & \\
303 & -669.983 & 0.2660 & & & \\
308 & -374.53 & 0.1463 & & &
\end{tabular}

on the RBC-TiO $\mathrm{TiC}_{2}$ nanocomposites was favorable and spontaneous. ${ }^{48}$ Moreover, the $\Delta G^{0}$ values increased with an increase in temperature, which indicated that the adsorption process is more spontaneous at lower temperature. The enthalpy change $\left(\Delta H^{0}\right)$ for the adsorption of $\mathrm{Cr}(\mathrm{vI})$ ions is 167.55 . The positive value suggests that the adsorption process is endothermic. The entropy change $\left(\Delta S^{0}\right)$ for the adsorption of $\mathrm{Cr}(\mathrm{vI})$ ions is 0.524 ; the positive value suggests that the randomness increased during the adsorption process. ${ }^{\mathbf{1 1 , 4 8}}$

\section{Conclusion}

In summary, we have developed a wet chemical coating process, followed by a one-step heating route for the novel synthesis of the RBC-TiO ${ }_{2} @ \mathrm{C}$ nanocomposite and estimated its potential to remove $\mathrm{Cr}(\mathrm{vI})$ from aqueous medium. Initially, the as-prepared $\mathrm{RBC}^{-\mathrm{TiO}_{2}}$ @C nanocomposite was characterized to confirm the fabrication of carbon and iron on the surface of nanocomposite by an array of techniques, namely, TEM, HRTEM, TEM-EDS, XRD, FTIR, BET and TGA. Furthermore, the sorption mecha-

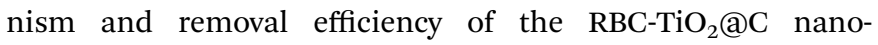
composites for $\mathrm{Cr}(\mathrm{vI})$ ions were investigated. The results revealed that adsorption of $\mathrm{Cr}(\mathrm{vI})$ was very fast and efficient with the RBC-TiO ${ }_{2} @ \mathrm{C}$ nanocomposites and the correlation coefficient $\left(r^{2}\right)$ for all four models was near unity. However, the best fit model for different $\mathrm{Cr}(\mathrm{vI})$ concentrations is the Langmuir model. Moreover, the data for various temperatures was well fit to the Temkin isotherm model. The Gibb's free energy values at all five temperatures were negative indicating the favorable and spontaneous adsorption of $\mathrm{Cr}$ ions on the $\mathrm{RBC}^{-\mathrm{TiO}_{2} @ \mathrm{C} \text { nano- }}$ composites. Conclusively, our results provide insights regarding the synthesis and $\mathrm{Cr}(\mathrm{vI})$ removal efficiency of RBC$\mathrm{TiO}_{2} @ \mathrm{C}$ nanocomposites in a broad $\mathrm{pH}$ range.

\section{Conflicts of interest}

There are no conflicts to declare.

\section{Acknowledgements}

The authors greatly acknowledge the National Basic Research Program of China (973 Program, 2014CB238903), the National Natural Science Foundation of China (No. 41373110), the Fundamental Research Funds for the Central Universities (WK2080000103) and the China Postdoctoral Science Foundation (2018M632552) for financial support. The Chinese Academy of Science (CAS) is also acknowledged for providing the CAS-Foreign Young Scientist Award (2018FYB0002). We also greatly appreciate the thoughtful comments and valuable suggestions from anonymous reviewers for the improvement of this manuscript.

\section{References}

1 X. Huang, X. Hou, F. Song, J. Zhao and L. Zhang, Environ. Sci. Technol., 2016, 50, 1964-1972.

2 B. Li, F. Zhou, K. Huang, Y. Wang, S. Mei, Y. Zhou and T. Jing, Sci. Rep., 2016, 6, 1-9. 
3 L. Li, H. Duan, X. Wang and C. Luo, New J. Chem., 2014, 38, 6008-6016.

4 H. Wang, B. Gao, S. Wang, J. Fang, Y. Xue and K. Yang, Bioresour. Technol., 2015, 197, 356-362.

5 W. Ben Achiba, N. Gabteni, A. Lakhdar, G. D. Laing, M. Verloo, N. Jedidi and T. Gallali, Agric., Ecosyst. Environ., 2009, 130, 156-163.

6 B. Yousaf, G. Liu, Q. Abbas, R. Wang, M. Imtiaz and M. Ziaur-Rehman, Land Degrad. Dev., 2017, 28, 2596-2607.

7 G. Yu, Y. Lu, J. Guo, M. Patel, A. Bafana, X. Wang, B. Qiu, C. Jeffryes, S. Wei, Z. Guo and E. K. Wujcik, Adv. Compos. Hybrid Mater., 2018, 1, 56-78.

8 Y. Ma, L. Lv, Y. Guo, Y. Fu, Q. Shao, T. Wu, S. Guo, K. Sun, X. Guo, E. K. Wujcik and Z. Guo, Polymer, 2017, 128, 12-23.

9 X. Xu, H. Zhang, H. Lou, C. Ma, Y. Li, Z. Guo and H. Gu, Eng. Sci., 2018, 1, 46-54.

10 B. Yousaf, Amina, G. Liu, R. Wang, M. Imtiaz, M. S. Rizwan, M. Zia-ur-Rehman, A. Qadir and Y. Si, Chemosphere, 2016, 150, 79-89.

11 U. Baig, R. A. K. Rao, A. A. Khan, M. M. Sanagi and M. A. Gondal, Chem. Eng. J., 2015, 280, 494-504.

12 M. A. Hashim, S. Mukhopadhyay, J. N. Sahu and B. Sengupta, J. Environ. Manage., 2011, 92, 2355-2388.

13 M. R. Muthumareeswaran, M. Alhoshan and G. P. Agarwal, Sci. Rep., 2017, 7, 41423.

14 M. Muthukrishnan and B. K. Guha, Desalination, 2008, 219, 171-178.

15 S. A. El-Korashy, K. Z. Elwakeel and A. A. El-Hafeiz, J. Cleaner Prod., 2016, 137, 40-50.

16 J. Song, M. Zhang, A. Figoli, Y. Yin, B. Zhao, X.-M. Li and T. He, Environ. Sci.: Water Res. Technol., 2015, 1, 839-845.

17 Y.-P. Wang, P. Zhou, S.-Z. Luo, S. Guo, J. Lin, Q. Shao, X. Guo, Z. Liu, J. Shen, B. Wang and Z. Guo, Adv. Polym. Technol., 2018, 1-16.

18 P. Rao, Z. Sun, W. Zhang and W. Yao, RSC Adv., 2015, 5, 89545-89551.

19 A. S. Bhatt, P. L. Sakaria, M. Vasudevan, R. R. Pawar, N. Sudheesh, H. C. Bajaj and H. M. Mody, RSC Adv., 2012, 2, 8663-8671.

20 W. Li, D. Chen, F. Xia, J. Z. Y. Tan, P.-P. Huang, W.-G. Song, N. M. Nursam and R. a. Caruso, Environ. Sci.: Nano, 2016, 3, 94-106.

21 X. Tan, Q. Fan, X. Wang and B. Grambow, Environ. Sci. Technol., 2009, 43, 3115-3121.

22 R. Kumar and J. Chawla, Water Qual., Exposure Health, 2014, 5, 215-226.

23 M. Hua, S. Zhang, B. Pan, W. Zhang, L. Lv and Q. Zhang, J. Hazard. Mater., 2012, 211-212, 317-331.

24 M. L. Paul, J. Samuel, N. Chandrasekaran and A. Mukherjee, J. Environ. Chem. Eng., 2014, 2, 1937-1946.

25 B. I. Kharisov, H. V. Rasika Dias, O. V. Kharissova, V. Manuel Jiménez-Pérez, B. Olvera Pérez and B. Muñoz Flores, RSC Adv., 2012, 2, 9325-9358.

26 M. qin Jiang, Q. ping Wang, X. ying Jin and Z. liang Chen, J. Hazard. Mater., 2009, 170, 332-339.

27 A. Cincotti, A. Mameli, A. M. Locci, R. Orrù and G. Cao, Ind. Eng. Chem. Res., 2006, 45, 1074-1084.
28 J. Huang, Y. Cao, Q. Shao, X. Peng and Z. Guo, Ind. Eng. Chem. Res., 2017, 56, 10689-10701.

29 K. Gong, Q. Hu, L. Yao, M. Li, D. Sun, Q. Shao, B. Qiu and Z. Guo, ACS Sustainable Chem. Eng., 2018, 6, 7283-7291.

30 Y. He, S. Yang, H. Liu, Q. Shao, Q. Chen, C. Lu, Y. Jiang, C. Liu and Z. Guo, J. Colloid Interface Sci., 2018, 517, 40-51.

31 S. Babel and T. A. Kurniawan, Chemosphere, 2004, 54, 951967.

32 A. Al Nafiey, A. Addad, B. Sieber, G. Chastanet, A. Barras, S. Szunerits and R. Boukherroub, Chem. Eng. J., 2017, 322, 375-384.

33 F. Halouane, Y. Oz, D. Meziane, A. Barras, J. Juraszek, S. K. Singh, S. Kurungot, P. K. Shaw, R. Sanyal, R. Boukherroub, A. Sanyal and S. Szunerits, J. Colloid Interface Sci., 2017, 507, 360-369.

34 Z. Ruan, J. Wu, J. Huang, Z. Lin, Y. Li, Y. Liu, P. Cao, Y. Fang and G. Jiang, J. Mater. Chem. A, 2015, 3, 4595-4603.

35 H. Du, C. X. Zhao, J. Lin, J. Guo, B. Wang, Z. Hu, Q. Shao, D. Pan, E. K. Wujcik and Z. Guo, Chem. Rec., 2018, DOI: 10.1002/tcr.201800008, in press.

36 Z. Hu, Q. Shao, Y. Huang, L. Yu, D. Zhang, X. Xu, J. Lin, H. Liu and Z. Guo, Nanotechnology, 2018, 29, 185602.

37 K. Sun, R. Fan, X. Zhang, Z. Zhang, Z. Shi, N. Wang, P. Xie, Z. Wang, G. Fan, H. Liu, C. Liu, T. Li, C. Yan and Z. Guo, J. Mater. Chem. C, 2018, 6, 2925-2943.

38 Y. Guo, G. Xu, X. Yang, K. Ruan, T. Ma, Q. Zhang, J. Gu, Y. Wu, H. Liu and Z. Guo, J. Mater. Chem. C, 2018, 6, 30043015.

39 P. Xie, Z. Wang, Z. Zhang, R. Fan, C. Cheng, H. Liu, Y. Liu, T. Li, C. Yan, N. Wang and Z. Guo, J. Mater. Chem. C, 2018, 6, 5239-5249.

40 Q. Luo, H. Ma, Q. Hou, Y. Li, J. Ren, X. Dai, Z. Yao, Y. Zhou, L. Xiang, H. Du, H. He, N. Wang, K. Jiang, H. Lin, H. Zhang and Z. Guo, Adv. Funct. Mater., 2018, 28, 1706777.

41 Q. Luo, H. Ma, F. Hao, Q. Hou, J. Ren, L. Wu, Z. Yao, Y. Zhou, N. Wang, K. Jiang, H. Lin and Z. Guo, Adv. Funct. Mater., 2017, 27, 1703068.

42 J. Ananpattarachai and P. Kajitvichyanukul, J. Cleaner Prod., 2016, 130, 126-136.

43 X. Cui, G. Zhu, Y. Pan, Q. Shao, C. (xinxin) Zhao, M. Dong, Y. Zhang and Z. Guo, Polymer, 2018, 138, 203-210.

44 H. Kang, Z. Cheng, H. Lai, H. Ma, Y. Liu and X. Mai, Sep. Purif. Technol., 2018, 201, 193-204.

45 P. Li, T. Wang, F. Lei, Q. Zeng, H. Li and J. Jiang, J. Mol. Catal. B: Enzym., DOI: 10.1016/j.molcatb.2016.12.003.

46 Z. M. Lei, Q. D. An, Y. Fan, J. L. Lv, C. Gao, S. R. Zhai and Z. Y. Xiao, New J. Chem., 2016, 40, 1195-1204.

47 E. P. Barrett, L. G. Joyner and P. P. Halenda, J. Am. Chem. Soc., 1951, 73, 373-380.

48 J. Wang, G. Liu, T. Li and C. Zhou, RSC Adv., 2015, 5, 2985929871.

49 J. He, Y. Long, Y. Wang, C. Wei and J. Zhan, ACS Appl. Mater. Interfaces, 2016, 8, 16699-16707.

50 W. Qian, L. Wei, F. Cao, Q. Chen and W. Qian, Carbon, 2006, 44, 1303-1307.

51 Y. Yang, G. Wang, Q. Deng, D. H. L. Ng and H. Zhao, ACS Appl. Mater. Interfaces, 2014, 3008-3015. 
52 J. Dui, G. Zhu and S. Zhou, ACS Appl. Mater. Interfaces, 2013, 5, 10081-10089.

53 R. Sahraei, Z. Sekhavat Pour and M. Ghaemy, J. Cleaner Prod., 2017, 142, 2973-2984.

54 A. N. Mondal, C. Dai, J. Pan, C. Zheng, M. M. Hossain, M. I. Khan, L. Wu and T. Xu, ACS Appl. Mater. Interfaces, 2015, 7, 15944-15954.

55 L. Hu, Y. Li, X. Zhang, Y. Wang, L. Cui, Q. Wei, H. Ma, L. Yan and B. Du, Sci. Rep., 2016, 6, 28924.

56 N. Sankararamakrishnan, M. Jaiswal and N. Verma, Chem. Eng. J., 2014, 235, 1-9.

57 E. I. El-Shafey, Water, Air, Soil Pollut., 2005, 163, 81-102.
58 B. Kiran, A. Kaushik and C. P. Kaushik, Chem. Eng. J., 2007, 126, 147-153.

59 A. R. Cestari, E. F. S. Vieira, J. D. S. Matos and D. S. C. Dos Anjos, J. Colloid Interface Sci., 2005, 285, 288-295.

60 Z. H. Yang, S. Xiong, B. Wang, Q. Li and W. C. Yang, J. Cent. South Univ., 2013, 20, 1319-1325.

61 X. Y. Yu, T. Luo, Y. Jia, Y. X. Zhang, J. H. Liu and X. J. Huang, J. Phys. Chem. C, 2011, 115, 22242-22250.

62 S.-C. Jang, S.-M. Kang, Y. Haldorai, K. Giribabu, G.-W. Lee, Y.-C. Lee, M. S. Hyun, Y.-K. Han, C. Roh and Y. S. Huh, Sci. Rep., 2016, 6, 38384.

63 J. Wang, G. Liu, T. Li and C. Zhou, RSC Adv., 2015, 5, 2985929871. 